\title{
Electrodeposition and Electroless Deposition of Metallic Powders: A Comparison
}

\author{
S. S. Djokicí ${ }^{1}$, N.D. Nikolić ${ }^{2}$, P.M. Živković ${ }^{3}$, K.I. Popov ${ }^{2,3}$ and N.S. Djokić ${ }^{1}$ \\ ${ }^{1}$ Elchem Consulting Ltd., Edmonton, Alberta, T5X 6B3, Canada, \\ ${ }^{2}$ ICTM-Inst. of Electrochemistry, University of Belgrade, Njegoševa 12, Belgrade, Serbia, \\ ${ }^{3}$ Faculty of Technology and Metallurgy, University of Belgrade, Karnegijeva 4, Belgrade, Serbia
}

Electrodeposition and electroless deposition of metallic powders were comparatively investigated. Electrodeposition of copper is accompanied with the simultaneous hydrogen evolution, which significantly influences the morphology of $\mathrm{Cu}$ powder. At lower overpotentials, branched dendrites were produced. At higher overpotentials honeycomb-like deposits of copper were obtained. Formation of silver powders was characterized by the comparison of the exchange and limiting current densities. Instantaneous growth of dendrites starts at low overpotential due to large exchange current density in silver nitrate solution. Formation of powders such as $\mathrm{Ni}, \mathrm{Co}, \mathrm{Ag}, \mathrm{Pd}$ and $\mathrm{Au}$ from homogenous solutions using an appropriate reducing agent or via galvanic displacement reaction was demonstrated. The hydrolysis of metallic ions is crucial in the deposition metallic powders via electroless deposition from homogenous solutions. Oxides, such as $\mathrm{Ag}_{2} \mathrm{O}, \mathrm{Cu}_{2} \mathrm{O}$ and $\mathrm{CuO}$, suspended in water can successfully be reduced with an appropriate reducing agent, leading to the precipitation of metallic powders.

\section{Introduction}

Powders are finely divided solids, smaller than $1000 \mu \mathrm{m}$ in its maximum dimension. A particle is defined as the smallest unit of a powder. The size of particles of many metal powders can vary widely ranging from a few nanometers to several hundreds of micrometers. Different methods for the production of metal powders including mechanical, chemical and electrolytic are used in practice (1). The electrodeposited metal powders are of high purity and are extremely "active" during sintering.

Powders of about 60 metals can successfully be produced by electrolysis. The majority of metallic powders are obtained by molten-salts electrolysis. However, due to technological advantages and various industrial applications, most of the practically useful powders, e.g., copper, iron, nickel etc., are produced from aqueous solutions (2).

Electrodeposited metallic powders are mainly produced in a dendritic form. The dendrites can spontaneously fall off or can be removed from the electrode by tapping or other similar techniques. Also, depending on the conditions of electrodeposition and on the nature of the metal, the powders can be obtained as flakes or needles, fibrous or spongy forms, etc..

All metals, which can be electrodeposited, usually appear in the form of powders at current densities larger than a certain critical value $i_{\mathrm{p}}$. This value is equal to the limiting diffusion current density in galvanostatic deposition, as shown by Ibl (3). The 
product of the employed current density and the square root of the time of powder formation, $t_{\mathrm{p}}$, is a constant quantity (4). This dependence is related to the diffusion controlled process and the time of powder formation coincides with the transition time. The time for powder formation at current densities equal to or larger than $i_{\mathrm{p}}$ can be observed visually: the working electrode turns suddenly from lustrous to black.

The above discussion is valid for galvanostatic powder electrodeposition. Because of the increase in real surface area of the electrode, the working current density should be many times larger than limiting diffusion one (5). In this way, the decrease in the current density below the limiting diffusion one can be avoided. Hence, hydrogen co-deposition in galvanostatic powder electrodeposition is inevitable.

The situation is somewhat different under the potentiostatic conditions. In this regime, dendrites of deposited metal also appear in the limiting diffusion current density range. However, hydrogen co-deposition is not a necessary factor for the powder formation of some metals $(6,7)$. In the absence of vigorous hydrogen evolution, powder particles are well developed dendrites or parts of them. At overpotentials larger than that of vigorous hydrogen evolution, the conditions of the powder formation become similar to those in galvanostatic deposition.

There are at least two basic consequences of the vigorous hydrogen evolution on the metal powder particles formation. First, the hydrodynamic regime in the vicinity of the electrode can be changed due to stirring of the solution by evolved hydrogen, thus resulting in the increase of the limiting diffusion current density (8). This causes the formation of morphological forms appearing before dendrite growth initiation at specified overpotential. Second, the formation of hydrogen bubbles strongly influences the current density distribution over electrode surface, and hence, the powder particles formation ( 9 , 10). The effect of different conditions of electrodeposition on the shape and structure of powder particles is clearly demonstrated in detail in Ref. (11).

Without an application of the external current, metallic powders can be formed from aqueous solutions either via galvanic displacement (cementation or immersion plating) or using an appropriate reducing agent $(12,13)$.

In the galvanic displacement reaction, the ions of more noble metal are reduced with the less noble metal according to the reaction:

$\mathrm{M}_{1}^{\mathrm{z}_{1}^{+}}+\frac{\mathrm{z}_{1}}{\mathrm{z}_{2}} \mathrm{M}_{2} \rightarrow \frac{\mathrm{z}_{1}}{\mathrm{z}_{2}} \mathrm{M}_{2}^{\mathrm{z}_{2}^{+}}+\mathrm{M}_{1}$

where $M_{1}$ represents the more noble metal and $M_{2}$ is the less noble metal. In this way, the less noble metal in terms of electroless deposition acts as a reducing agent of ions of a more positive metal. Typical examples for this type of deposition include $\mathrm{Fe} / \mathrm{Cu}^{2+}$, $\mathrm{Al} / \mathrm{Ag}^{+}, \mathrm{Al} / \mathrm{Cu}^{2+}$ etc. In an ideal thermodynamic case, as soon as the surface of the less noble metal is covered with a film of the more noble metal, the deposition should stop. However, as experimentally seen, this is not the case. In this kind of deposition not only thicker than a monolayer coatings can be achieved, but powders as well $(13,14)$.

At the beginning i.e., immediately upon the immersion, the rate of the deposition is the fastest, since the whole surface, or more active sites are available for the reaction. As the surface of the less noble metal is covered with the more noble metal, the rate of deposition progressively decreases, since smaller number of sites of the less noble metal is in the contact with solution. Due to porosity, or uneven coating, the deposition of the more noble metal will continue as long as the surface of the less noble metal is in contact with the solution On the other hand, when the less noble metal is completely consumed, 
then electrons cannot be produced as a consequence of its dissolution (Equation 1). In this case the deposition stops.

Various types of the surface morphology and different shapes or sizes of powders can be obtained using this technique of deposition (15). The growth of particles of the more noble metal depends on the conditions such as the type of the electrolyte, metal being deposited, temperature, $\mathrm{pH}$ etc. The galvanic deposition is quite successfully used in hydrometallurgical or electroplating plants for metal removal or electrolyte purifications (7).

During the electroless deposition from homogenous aqueous systems, formation of metallic powders into the bulk solution is usually seen when the concentration of the reducing agent is too high or at elevated temperatures. The deposition of thin films proceeds only onto catalytic or previously activated metallic or non-metallic surfaces. It is important to note that the deposition temperature and concentration of the reducing agent, complexing agents, buffering agents, stabilizers etc., must be very carefully controlled in order to produce the thin smooth films on properly activated metallic or non-metallic surfaces $(12,13,16)$. The formation of powders is observed both, at the activated surface or into the bulk solution. The growth of particles is obviously catalyzed by the metal being deposited which is the same as the autocatalytic deposition. Both, an increased concentration of the reducing agent and an elevated temperature lead to the socalled bath instability, a consequence of the powder formation $(12,13,16)$. As such, the deposition of powders does not necessarily require the activation.

In the present work the electrodeposition and electroless deposition of metallic powders is presented and compared.

\section{Experimental}

\section{Copper electrodeposition}

Copper was electrodeposited from $0.075 \mathrm{M} \mathrm{CuSO}_{4}+0.50 \mathrm{M} \mathrm{H}_{2} \mathrm{SO}_{4}$ solution at overpotentials 650 and $1000 \mathrm{mV}$ on vertical cylindrical copper electrodes. In all experiments, the geometric surface area of copper electrodes was $0.50 \mathrm{~cm}^{2}$. The polarization curve for copper electrodeposition was recorded using a platinum cylindrical electrode on which a thin copper film was electrodeposited from the same solution at the overpotential of $250 \mathrm{mV}$ for $5 \mathrm{~min}$. The counter and reference electrodes were made of pure copper.

\section{$\underline{\text { Silver electrodeposition }}$}

Silver was electrodeposited from $0.1 \mathrm{M} \mathrm{AgNO}_{3}+0.5 \mathrm{M}\left(\mathrm{NH}_{4}\right)_{2} \mathrm{SO}_{4}+0.5 \mathrm{M} \mathrm{NH}_{3}$ solution, at overpotentials 650 and $1000 \mathrm{mV}$, and from $0.06 \mathrm{M} \mathrm{AgNO}_{3}+1.2 \mathrm{M} \mathrm{NaNO}_{3}$ $+0.05 \mathrm{M} \mathrm{HNO}_{3}$ solution at the overpotential of $150 \mathrm{mV}$, on vertical cylindrical graphite electrodes. The geometric surface area of graphite electrodes was $0.31 \mathrm{~cm}^{2}$. Polarization curves for silver electrodeposition were recorded using platinum cylindrical electrodes covered with thin silver film. This thin silver film was electrodeposited from $0.1 \mathrm{M}$ $\mathrm{AgNO}_{3}+0.5 \mathrm{M}\left(\mathrm{NH}_{4}\right)_{2} \mathrm{SO}_{4}+0.5 \mathrm{M} \mathrm{NH}_{3}$ solution at the overpotential of $150 \mathrm{mV}$ for 5 min. The counter and reference electrodes were made of pure silver. 
Doubly distilled water and analytical grade chemicals were used for the preparation of the solutions for electrodeposition of copper and silver. All experiments were performed in an open cell at a temperature of about $18{ }^{\circ} \mathrm{C}$. The counter electrodes were corresponding metallic foils with $0.80 \mathrm{dm}^{2}$ surface area and placed close to the cell walls. The reference electrodes were wires of the corresponding metals whose tips were positioned at a distance of about $2 \mathrm{~mm}$ from the surface of the working electrodes. The working electrodes were placed in the centre of cell, at the same location for each experiment.

\section{$\underline{\text { Electroless Deposition }}$}

For the galvanic deposition, an Al foil was used to deposit silver powders from the acidic or alkaline solutions containing $\mathrm{Ag}(\mathrm{I})$ ions. The details for deposition of $\mathrm{Ag}$ powders via galvanic deposition are given in the Results and Discussion section.

Other powders produced in the present work from homogenous aqueous solutions without an external current source included $\mathrm{Ag}, \mathrm{Cu}, \mathrm{Ni}, \mathrm{Co}, \mathrm{Au}$ and $\mathrm{Pd}$. These powders were synthesized using the formulations for the electroless deposition available in the literature $(12,13,16)$. The conditions for the formation of powders were sought in socalled bath instability (either elevated temperatures, or increased concentrations of the reducing agents). In all experiments, analytical grade chemicals and distilled water were used. The reducing agents used in the present work included formaldehyde, hydrazine, sodium hypophosphite and ascorbic acid.

After deposition, powders were separated from the slurry, very carefully washed several times with the distilled water and then with ethanol. Powders were stored afterwards under the ethanol for further examinations.

Electrochemically or electroless deposited powders were analyzed by the scanning electron microscopy (SEM) or, where required, by the x-ray diffraction (XRD).

\section{Results and Discussion}

\section{Copper powder}

Figure 1 shows the polarization curve for copper electrodeposition from $0.075 \mathrm{M} \mathrm{CuSO}_{4}$ in $0.50 \mathrm{M} \mathrm{H}_{2} \mathrm{SO}_{4}$ solution. The range of overpotentials belonging to the plateau of the limiting diffusion current density is estimated to be between 140 and $750 \mathrm{mV}$. Hydrogen evolution, as the simultaneous reaction in the copper electrodeposition, starts at some overpotential belonging to the plateau of the limiting diffusion current density. Increasing overpotential intensifies the hydrogen evolution reaction and at some overpotential outside the plateau of the limiting diffusion current density, hydrogen evolution becomes vigorous enough to disturb the hydrodynamic conditions in the nearelectrode layer (8). The critical amount of evolved hydrogen that is responsible for the change of hydrodynamic conditions in the near-electrode layer was estimated to correspond to the average current efficiency of hydrogen evolution of $10.0 \%$ (9), for solutions containing $0.15 \mathrm{M} \mathrm{CuSO}_{4}$ and less (in $0.50 \mathrm{M} \mathrm{H}_{2} \mathrm{SO}_{4}$ ). 


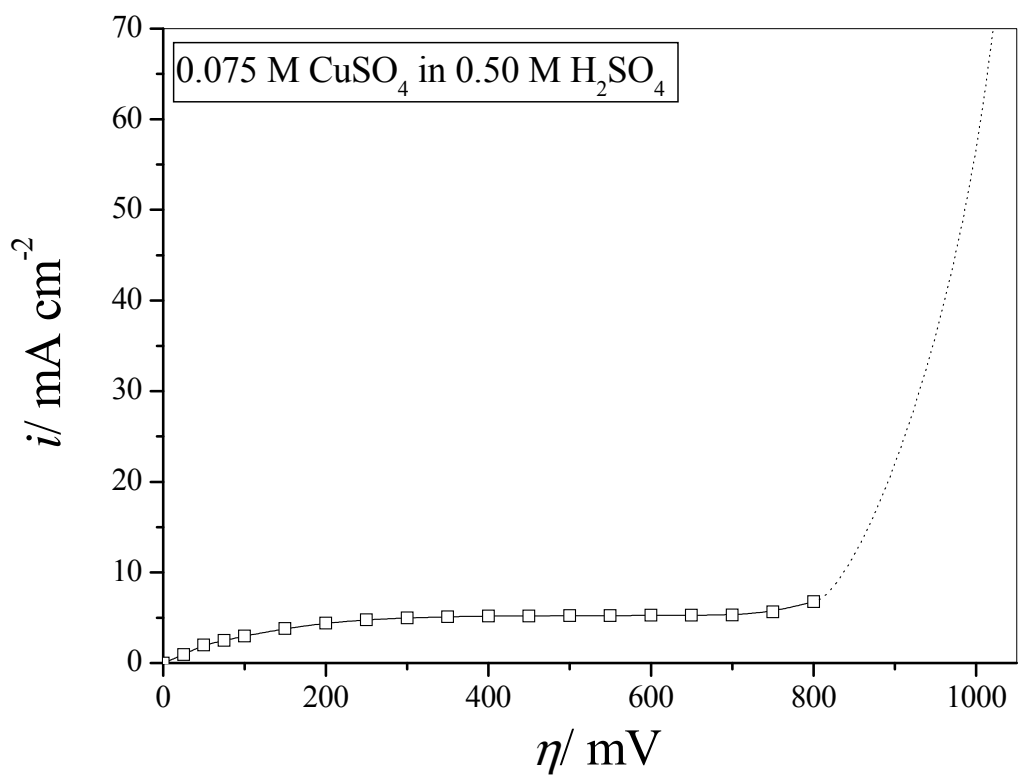

Figure 1. Polarization curve for copper electrodeposition from $0.075 \mathrm{M} \mathrm{CuSO}_{4}$ in $0.50 \mathrm{M}$ $\mathrm{H}_{2} \mathrm{SO}_{4}$.

The typical powdered deposits obtained at the overpotential of $650 \mathrm{mV}$ (plateau of the limiting diffusion current density) and at the overpotential of $1000 \mathrm{mV}$ (about 250 $\mathrm{mV}$ outside of the plateau) are shown in Figures $2 \mathrm{a}$ and $2 \mathrm{~b}$, respectively. The macro structure of the formed copper deposits is obviously very different. Very branched dendrites and cauliflower-like agglomerates of copper grains were formed by the electrodeposition at the overpotential of $650 \mathrm{mV}$ (Figure 2a). The formation of this deposit is accompanied with the quantity of evolved hydrogen insufficient to change the hydrodynamic conditions in the near-electrode layer. The amount of hydrogen evolved for this case corresponds to an average current efficiency of hydrogen evolution of $7.5 \%$ (9).

At the overpotential of $1000 \mathrm{mV}$, holes formed by attached hydrogen bubbles surrounded by cauliflower-like agglomerates of copper grains were found. This type of copper structure is denoted as honeycomb-like (8) (Figure 2b). The process by which this deposit was formed is accompanied with a sufficient hydrogen evolution in order to change the hydrodynamic conditions in the near-electrode layer. An average current efficiency of hydrogen evolution of $68.7 \%$ for this case was reported (17). 


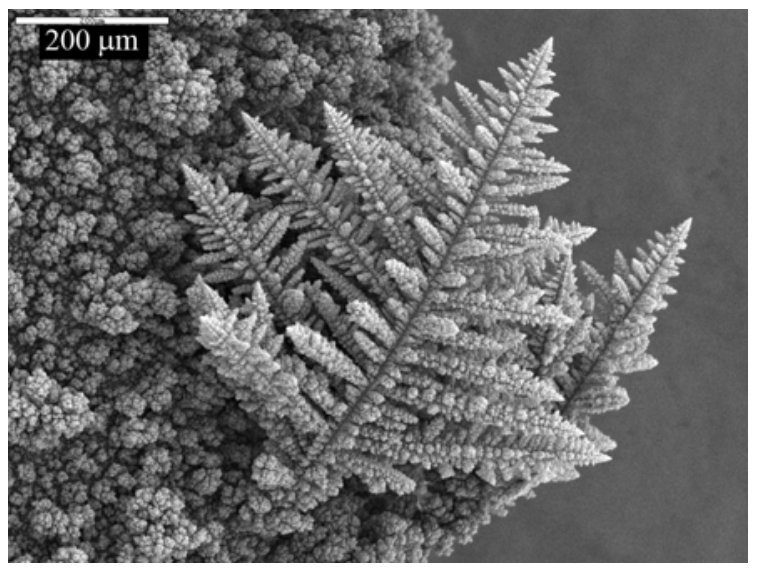

a)

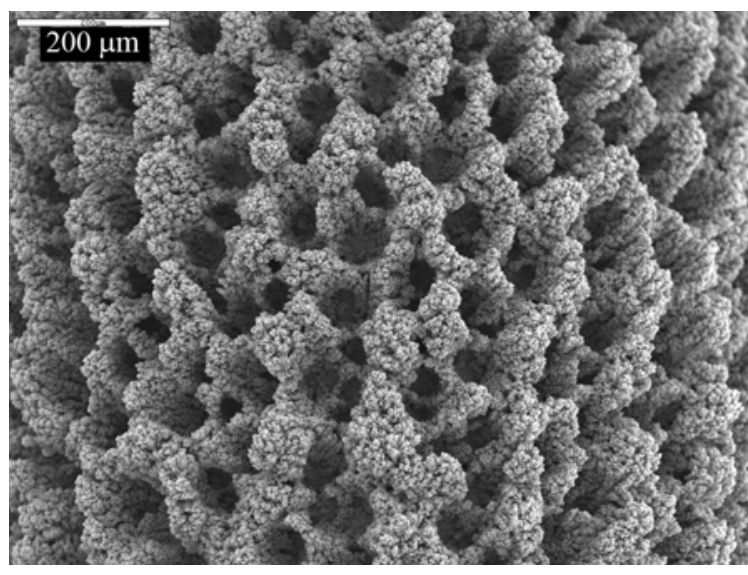

b)

Fig. 2. Macro structures of copper powdered deposits electrodeposited at overpotentials of: a) $650 \mathrm{mV}$; b) $1000 \mathrm{mV}$.

An image of the dendritic particle obtained by tapping the copper deposit presented in Figure 2a is shown in Figure 3a. The dendritic character of this particle is made of the corncob-like elements as presented by images in Figures $3 b$ and $3 c$. The ultrasonic treatment of copper dendrites showed that the corncob-like forms were the basic elements of which copper dendrites are composed (10). A further analysis of the corncob-like elements at the micro level found that they are composed of small agglomerates of copper grains (Figure $3 \mathrm{~d}$ ).

The electrodeposition where the formation of highly branched dendritic particles takes place is rather diffusion, than electron transfer controlled process (7). The formation of very branched dendrites and cauliflower-like agglomerates clearly indicates the lack of the amount of evolved hydrogen to disturb the diffusion layer of the macroelectrode during electrodeposition at the overpotential of $650 \mathrm{mV}$.

A particle obtained by tapping the copper deposit electrodeposited at the overpotential of $1000 \mathrm{mV}$ is shown in Figure 4a. Channel structure generated through the interior of the particle in situ by the simultaneous processes of copper nucleation and strong hydrogen evolution can be easily seen from Figure 4a. This type of powder consists of an aggregate of small cauliflower-like particles (Figure 4b). Top view of the powder shown in Figure 4a clearly revealed its cauliflower-like character (Figure 4c). An analysis of the cauliflower-like forms at the micro level showed that they were composed of small agglomerates of copper grains (Figure 4d). When this powder was ultrasonically treated the results showed that the basic element of these particles has the shape of a degenerate dendrite (10). 


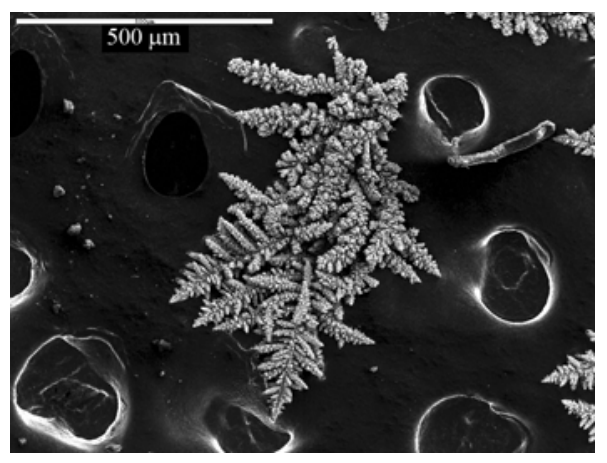

a)

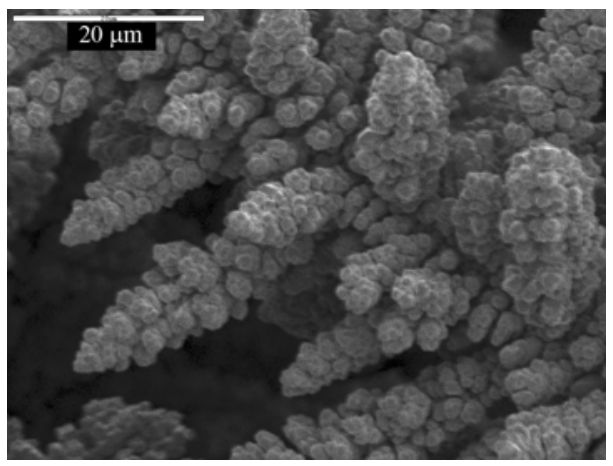

c)

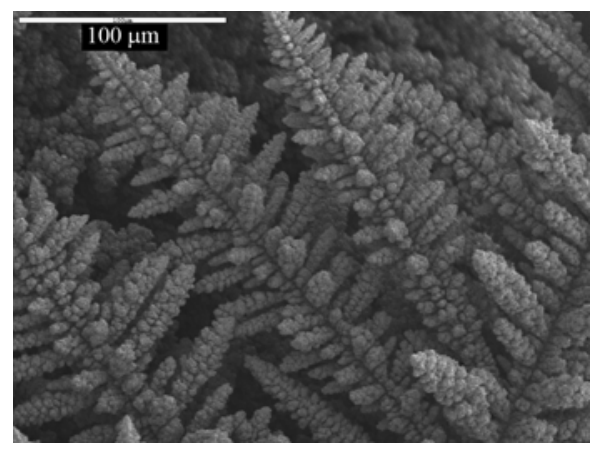

b)

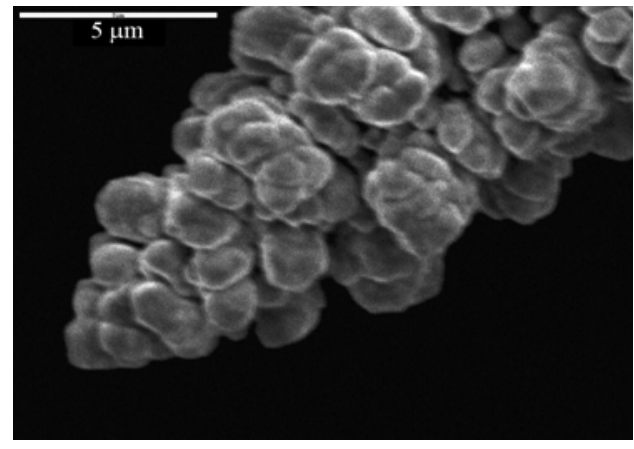

d)

Fig. 3. a) Dendritic particle obtained by tapping the copper deposit electrodeposited at an overpotential of $650 \mathrm{mV}$; b) and c) corncob-like elements of which dendrites are composed; and d) micro structure of the corncob-like element.

The particles shown in Figures $3 \mathrm{~d}$ and $4 \mathrm{~d}$ were obtained under different hydrodynamic conditions i.e., with quite significant differences in current efficiency for hydrogen evolution, as explained above. Despite the differences in the conditions the surface morphology of these particles is very similar at the micro level. The obvious difference is in the size of the individual copper grains of which the particles are consisted. The smaller size of the individual copper grains produced at the overpotential of $1000 \mathrm{mV}$ in comparison with the size of those deposited at $650 \mathrm{mV}$ is attributable to the higher nucleation rate at an increased overpotential.

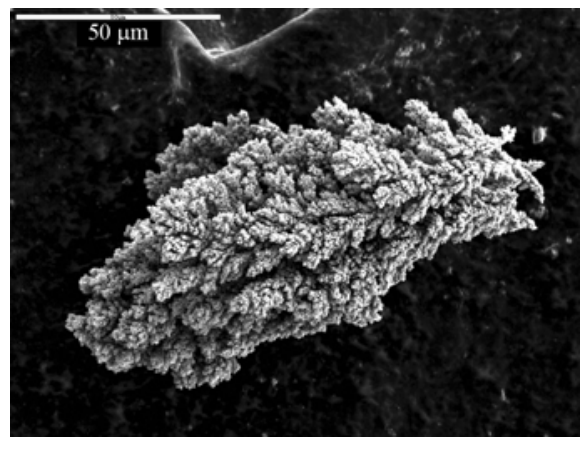

a)

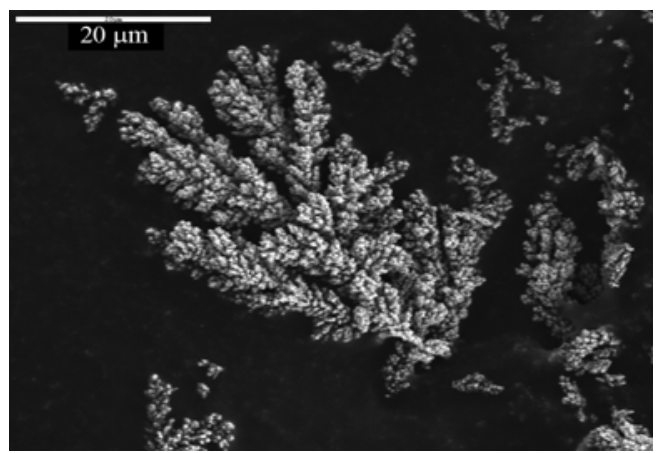

b) 


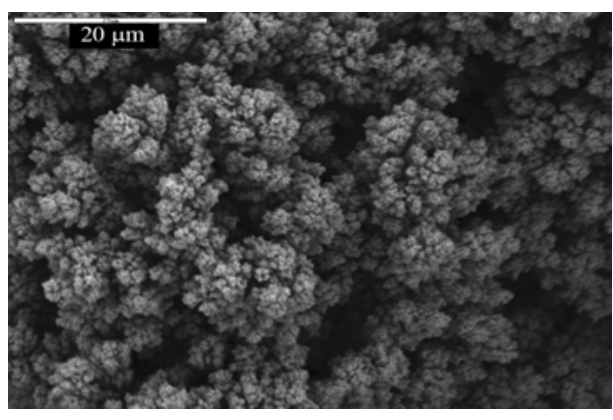

c)

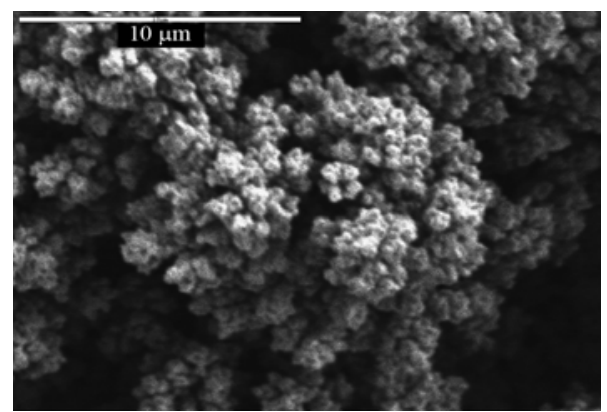

d)

Fig. 4. a) Powder particle obtained by tapping the copper deposit electrodeposited at an overpotential of $1000 \mathrm{mV}$; b) and c) cauliflower-like character of this type of the powder particle; and d) micro structure of the cauliflower-like particle.

Mechanism of the particles formation with a vigorous simultaneous hydrogen evolution, as seen during copper electrodeposition at the overpotential of $1000 \mathrm{mV}$, is completely different from the one when the hydrogen evolution was not sufficient to disturb the diffusion layer of the macroelectrode. The vigorous hydrogen evolution causes stirring of the solution in the near-electrode layer leading to a decrease of the cathode diffusion layer thickness and to an increase of the limiting diffusion current density (8). To explain the formation of this type of particles, the concept of ,effective overpotential" was proposed (8). According to this concept, at overpotentials at which hydrogen evolution is competitive with the metal electrodeposition, the hydrogen bubbles change the hydrodynamic conditions in the near-electrode layer. On the other hand, the metal electrodeposition occurs at an overpotential which is effectively lower than the specified one. Accordingly, this overpotential is denoted as the "effective overpotential" of the electrodeposition process. Due to the change in the hydrodynamic conditions caused by the vigorous hydrogen evolution, the morphologies of the deposits become similar to those obtained at some lower overpotential, before the initiation of dendritic growth (8). This successfully explains the cauliflower-like shape of the powder particles formed in all cases under conditions of vigorous hydrogen evolution (10).

$\underline{\text { Silver powder }}$

Polarization curve for silver electrodeposition from a solution containing $0.1 \mathrm{M} \mathrm{AgNO}_{3}$, $0.5 \mathrm{M}\left(\mathrm{NH}_{4}\right)_{2} \mathrm{SO}_{4}$ and $0.5 \mathrm{M} \mathrm{NH}_{3}$ is shown in Fig. 5. The plateau of the limiting diffusion current density corresponds to the range of overpotentials between 250 and $700 \mathrm{mV}$. At the first sight, the shape of polarization curve was very similar to the one previously observed for copper electrodeposition. For that reason, the formation of silver powders at same overpotentials i.e., 650 and $1000 \mathrm{mV}$ was analyzed. 


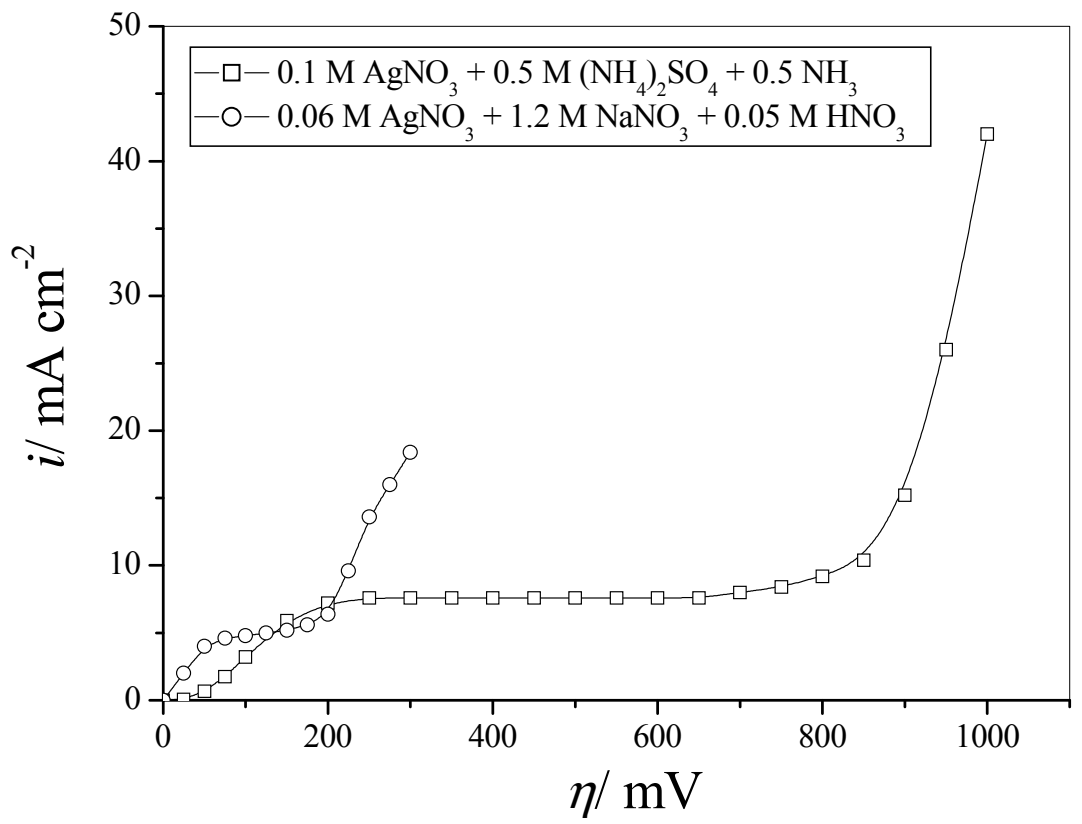

Figure 5. Polarization curves for silver electrodepositions from both $0.1 \mathrm{M} \mathrm{AgNO}_{3}+0.5$ $\mathrm{M}\left(\mathrm{NH}_{4}\right)_{2} \mathrm{SO}_{4}+0.5 \mathrm{M} \mathrm{NH}_{3}$ and $0.06 \mathrm{M} \mathrm{AgNO}_{3}+1.2 \mathrm{M} \mathrm{NaNO}_{3}+0.05 \mathrm{M} \mathrm{HNO}_{3}$.

The typical silver deposits obtained at overpotentials of 650 and $1000 \mathrm{mV}$ are shown in Figures $6 \mathrm{a}$ and $6 \mathrm{~b}$, respectively. Very branchy dendrites are produced at the overpotential of $650 \mathrm{mV}$ (Figure 6a), while sponge-like structure is formed at the overpotential of $1000 \mathrm{mV}$ (Figure 6b).

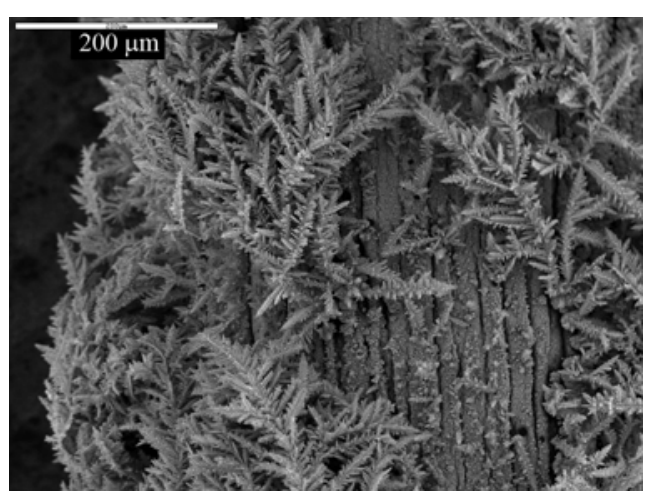

a)

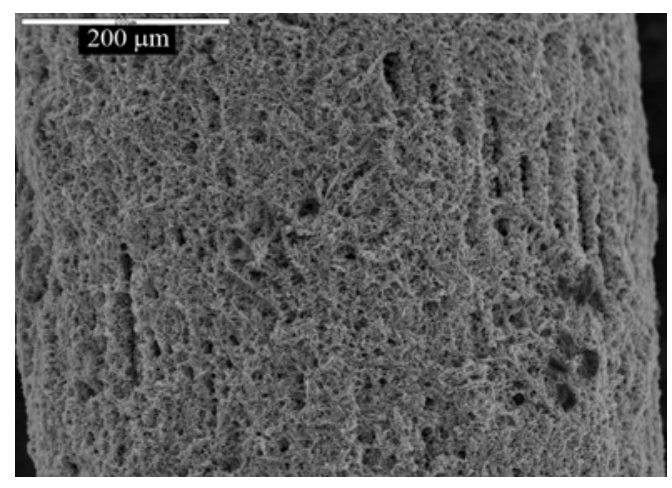

b)

Figure 6. Macro structures of silver powdered deposits electrodeposited at overpotentials of: a) $650 \mathrm{mV}$; b) $1000 \mathrm{mV}$.

The typical silver particles obtained by tapping the silver deposit (Figure 6a) are shown in Figure 7a. Analysis of silver dendrites shown in Figures 6a and 7a at higher magnifications revealed their similarity at both macro and micro level with copper dendrites illustrated in Figures 2a and 3. Silver dendrites are composed of corncob-like forms, while the corncob-like forms were built of small agglomerates of silver grains (Figures $7 b$ and c). 
At the first sight it is clear that the macro structure of the silver deposit formed at the overpotential of $1000 \mathrm{mV}$ was completely different than that of the copper electrodeposited at the same overpotential. Based on the images presented in Figure $2 \mathrm{~b}$ (copper) and Figure 6b (silver) the deposit of silver seems to be more compact and less porous in comparison to that of copper. An analysis of silver deposit produced at the overpotential of $1000 \mathrm{mV}$ with a higher magnification (Figure 8) showed that this material is dendritic in shape. Thus, the macro structure of silver powder formed at the overpotential of $1000 \mathrm{mV}$ is more similar to that of copper and silver deposited at 650 $\mathrm{mV}$ than to the macro structure of copper powder produced at $1000 \mathrm{mV}$. Silver dendrites electrodeposited at the overpotential of $1000 \mathrm{mV}$ were considerably smaller than those formed at the overpotential of $650 \mathrm{mV}$, which is attributed to higher nucleation rate at $1000 \mathrm{mV}$ than at $650 \mathrm{mV}$.

Formation of copper and silver powders by electrodeposition from electrolytes used in the present work is characterized by $i_{\mathrm{o}}<i_{\mathrm{L}}$, where $i_{\mathrm{O}}$ is the exchange current density and $i_{\mathrm{L}}$ is the limiting diffusion current density. In the case of silver, there is no simultaneous hydrogen evolution and the increase in current with the rising overpotential above $700 \mathrm{mV}$ can be ascribed to the instantaneous dendrite growth. The absence of hydrogen evolution during silver electrodeposition is explained by the fact that the equilibrium potential of silver electrode in silver ammonium solution is slightly more positive than the one of copper electrode in the copper sulfate solution (18). On the other hand, it is well known that hydrogen evolution reaction on copper electrode is somewhat faster than on silver electrode (19). Consequently, hydrogen evolution does not occur on silver electrode even at the overpotential of $1000 \mathrm{mV}$ vs. Ag reference electrode.

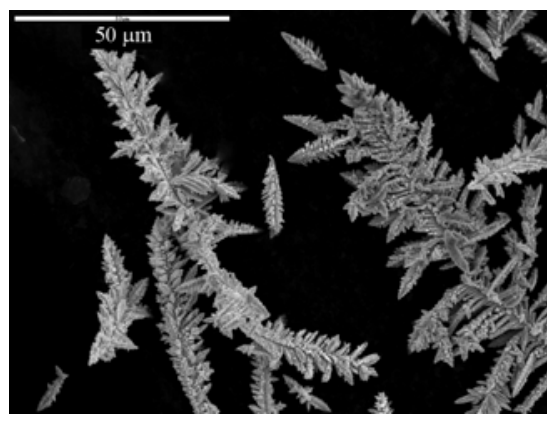

a)

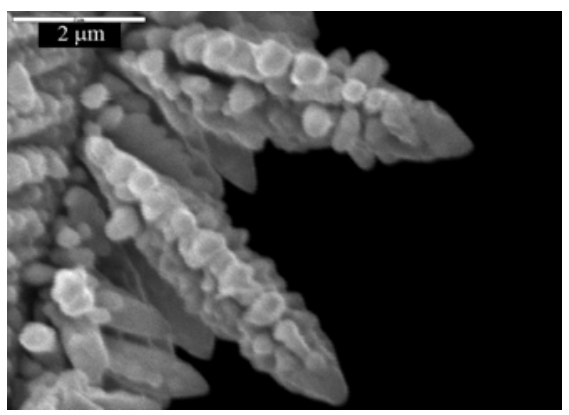

c)

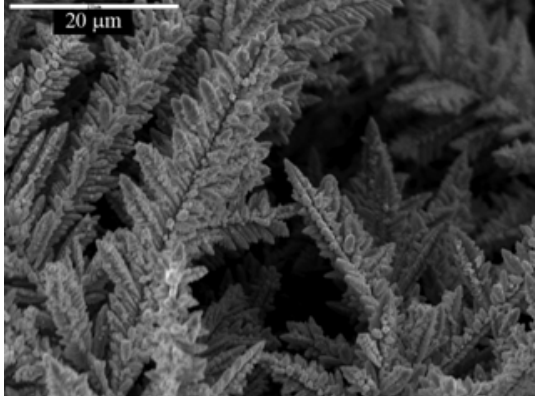

b)

Figure 7. a) Dendritic particles obtained by tapping the silver deposit electrodeposited at an overpotential of $650 \mathrm{mV}$ from $0.1 \mathrm{M} \mathrm{AgNO}_{3}$ in both $0.5 \mathrm{M}\left(\mathrm{NH}_{4}\right)_{2} \mathrm{SO}_{4}$ and $0.5 \mathrm{M}$ $\mathrm{NH}_{3}$; b) and c) the corncob-like elements of which dendrites are composed. 


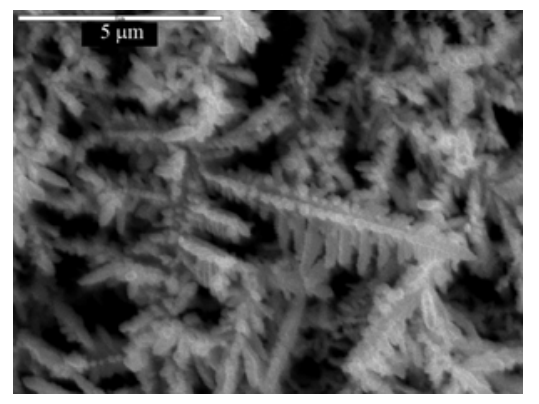

Figure 8. Dendritic particles obtained by silver electrodeposition from $0.1 \mathrm{M} \mathrm{AgNO}_{3}$ in both $0.5 \mathrm{M}\left(\mathrm{NH}_{4}\right)_{2} \mathrm{SO}_{4}$ and $0.5 \mathrm{M} \mathrm{NH}_{3}$ at an overpotential of $1000 \mathrm{mV}$.

Depending on the anion used, silver electrodeposition can also be characterized in terms of the relation, $i_{\mathrm{o}}>>i_{\mathrm{L}}$. The typical polarization curve for silver electrodeposition from $0.06 \mathrm{M} \mathrm{AgNO}_{3}, 1.2 \mathrm{M} \mathrm{NaNO}_{3}$ and $0.05 \mathrm{M} \mathrm{HNO}_{3}$ solution is shown in Figure 5 (denoted by "O"). As presented in this figure the shape of the polarization curve is completely different than the one obtained with an alkaline ammonium electrolyte in the presence of the sulfate anion. The plateau of the limiting diffusion current density was relatively narrower, corresponding to the range of overpotentials between 75 and $175 \mathrm{mV}$. Instantaneous growth of dendrites (7) starts at relatively low overpotential because of the large exchange current density in silver nitrate solutions (20), which is significantly higher than in the case of silver ammonium solution (21).

The silver powder electrodeposited from nitrate electrolyte at the overpotential of $150 \mathrm{mV}$ is shown in Figure 9a. Silver particles obtained by tapping this silver deposit from electrode surface represent a mixture of different morphological forms, as shown in Figures $9 \mathrm{~b}-\mathrm{d}$. Some of the particles had the shape of the two-dimensional (2D) dendrites (Figure. 9b). The presence of other morphological forms, such as crystals of irregular shape and needle-like particles (Figures 9c and $\mathrm{d}$ ), was also noticed. Morphologies of silver particles electrodeposited from nitrate solution were completely different than those formed during copper electrodeposition from sulfate electrolyte and silver electrodeposition from ammonium electrolyte. As in the case of ammonium electrolyte, silver electrodeposition from nitrate solution was not accompanied with hydrogen evolution reaction.

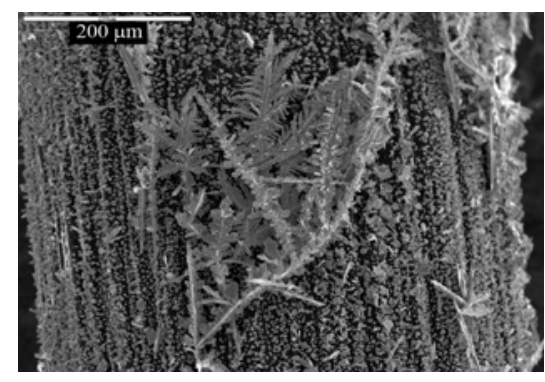

a)

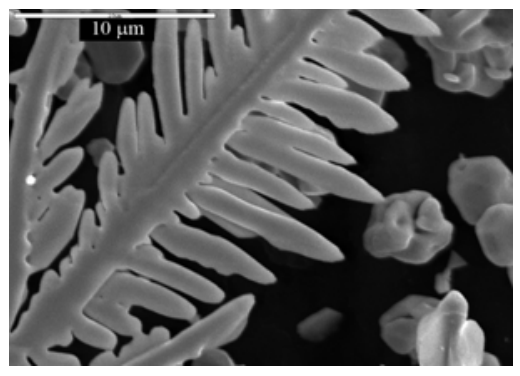

b) 


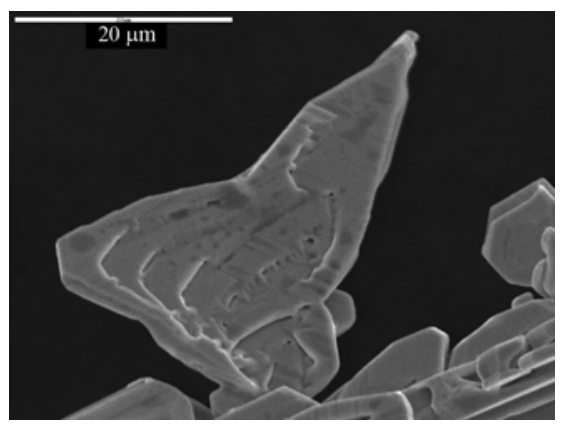

c)

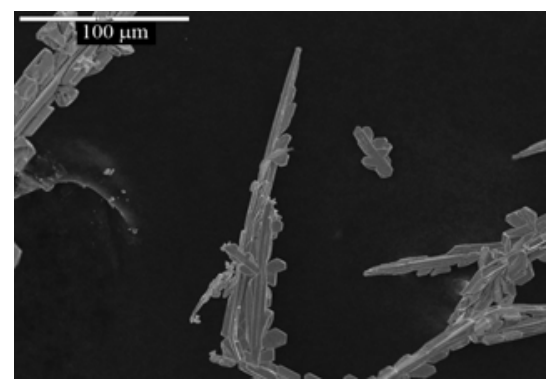

d)

Figure 9. a) Macro structure and b) - d) the typical morphological forms of silver obtained by electrodeposition from $0.06 \mathrm{M} \mathrm{AgNO}_{3}$ in both $1.2 \mathrm{M} \mathrm{NaNO}_{3}$ and $0.05 \mathrm{M}$ $\mathrm{HNO}_{3}$ at an overpotential of $150 \mathrm{mV}$.

The polarization curves for copper and silver electrodeposition from sulfate and ammonium solutions are similar to each other. Copper and silver dendrites, composed of the corncob-like elements, were electrodeposited from their respective solutions containing sulfate anions at the overpotential of $650 \mathrm{mV}$ (copper and silver) and at the overpotential of $1000 \mathrm{mV}$ (silver). The corncob-like forms are built of small agglomerates of copper or silver grains. These morphological forms were obtained when the electrodeposition was not accompanied with the simultaneous hydrogen evolution reaction (silver) or when hydrogen evolution was insufficient to disturb the diffusion layer of macroelectrode and causes the change of hydrodynamic conditions in the nearelectrode layer (copper). On the other hand, cauliflower-like particles composed of small agglomerates of copper grains that are formed around holes were electrodeposited at the overpotential of $1000 \mathrm{mV}$ when hydrogen evolution was enough vigorous to change hydrodynamic conditions in the near-electrode layer. The strong effect on the shape of polarization curves, as well as on morphology of silver particles was attained when sulfate anion was replaced with nitrate anion. Hence, for the same anion used, the shape or macro structure of the formed particles depends not on the nature of metal (copper or silver), but on the hydrodynamic conditions in the near-electrode layer. For the same metal, the shape of particles strongly depends on the kind of anion used, as clearly shown for silver (sulfate and nitrate anions).

\section{Galvanic Deposition of Metallic Powders}

The SEM images of $\mathrm{Ag}$ powder produced from a solution containing $0.01 \mathrm{M} \mathrm{AgNO}_{3}$ dissolved in a diluted $\mathrm{NH}_{4} \mathrm{OH}$ solution at $\mathrm{pH}$ of about 10 (a) or from a $0.01 \mathrm{M} \mathrm{AgNO}_{3}$ and $0.5 \mathrm{M}$ citric acid solution at $\mathrm{pH}$ of about 2 (b) by the galvanic deposition on an $\mathrm{Al}$ foil are presented in Figure 10. In the alkaline solutions $(\mathrm{pH} \mathrm{10)}$ on flat aluminum substrate globular powders of silver were produced (a), while in acidic solution $(\mathrm{pH} 2)$ dendritic (b). 


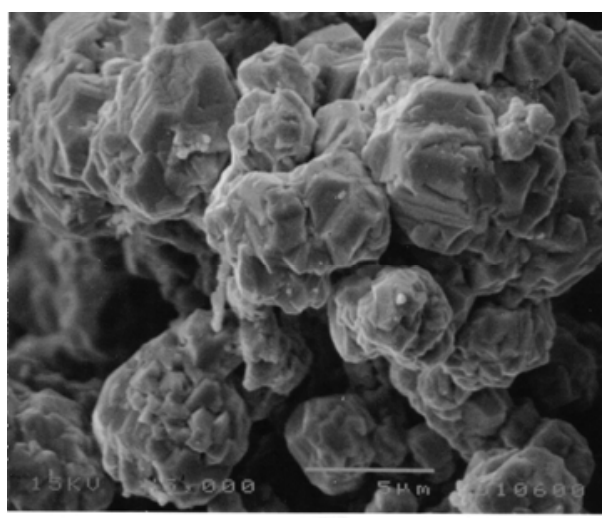

(a)

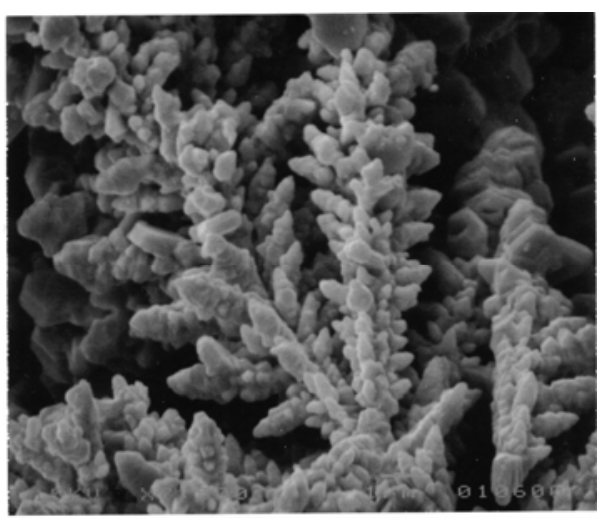

(b)

Figure 10. $\mathrm{Ag}$ powders produced via galvanic deposition from (a) $0.01 \mathrm{M} \mathrm{AgNO}$ dissolved in diluted $\mathrm{NH}_{4} \mathrm{OH}\left(\mathrm{pH} 10,22^{\circ} \mathrm{C}\right)$ and from (b) $0.01 \mathrm{M} \mathrm{AgNO}_{3}$ dissolved in 0.5 $\mathrm{M}$ citric acid solution $\left(\mathrm{pH} 2,22^{\circ} \mathrm{C}\right)$ on an aluminum foil.

The production of silver powder from an acidic solution using the aluminum foil can be explained with the following reaction:

$\mathrm{Ag}^{+}+2 \mathrm{H}^{+}+\mathrm{Al} \rightarrow \mathrm{Ag}+\mathrm{Al}^{3+}+\mathrm{H}_{2}$

Similarly, in alkaline solutions containing $\left[\mathrm{Ag}\left(\mathrm{NH}_{3}\right)_{2}\right]^{+}$ions, silver powder is produced onto aluminum foil via galvanic deposition according to the reaction:

$$
\left[\mathrm{Ag}\left(\mathrm{NH}_{3}\right)_{2}\right]^{+}+\mathrm{Al}+2 \mathrm{OH}^{-}+2 \mathrm{H}_{2} \mathrm{O} \rightarrow \mathrm{Ag}+\left[\mathrm{Al}(\mathrm{OH})_{4}\right]^{-}+\mathrm{H}_{2}+2 \mathrm{NH}_{3}
$$

It is worth to note that in both, acidic or alkaline conditions the simultaneous hydrogen evolution reaction takes place due to aluminum dissolution, which is experimentally seen as bubble formation.

In general terms, the experimental observations here suggest that the surface of the less noble metal is not uniformly covered with the more noble metal. Rather, the film of more noble metal is porous. The existence of pores allows the electrolyte to penetrate through and get in contact with the less noble metal. Under these conditions, when in the contact with an appropriate electrolyte, the less noble metal, $\mathrm{M}_{2}$, will dissolve according to the reaction:

$$
\mathrm{M}_{2} \rightarrow \mathrm{M}_{2}^{\mathrm{z}_{2}^{+}}+\mathrm{z}_{2} \mathrm{e}^{-}
$$

The produced electrons are further transferred and used for the reduction of ions of the more noble metal, $\mathrm{M}_{1}$ :

$$
\mathrm{M}_{1}^{\mathrm{z}_{1}^{+}}+\mathrm{z}_{1} \mathrm{e}^{-} \rightarrow \mathrm{M}_{1}
$$

The sum of the equations [4] and [5] gives the reaction [1], which describes the galvanic deposition. In this way the growth of the film or powders of the more noble metal occurs further. Due to porosity of the deposited metal, powders can be obtained via galvanic deposition even on flat substrates. Depending on the conditions, by this type of deposition different shapes of powders can be produced, as illustrated by Figure 10. 
It seems that the galvanic deposition produces powders when the simultaneous hydrogen evolution reaction takes place:

$2 \mathrm{H}^{+}+2 \mathrm{e}^{-} \rightarrow \mathrm{H}_{2}$

This is demonstrated for the examples of $\mathrm{Al} / \mathrm{Ag}$ in the present work or $\mathrm{Al} / \mathrm{Cu}$ in alkaline solutions (14). For other systems, in order to produce powders by this type of deposition it is necessary that the surface of the less noble metal is not completely covered by the more noble metal, i.e., when the coating is porous.

\section{Electroless Deposition of Metallic Powders from Homogenous Aqueous Solutions}

In Figure 11 are presented the SEM micrographs of $\mathrm{Cu}$ powders obtained by electroless deposition with formaldehyde as the reducing agent.
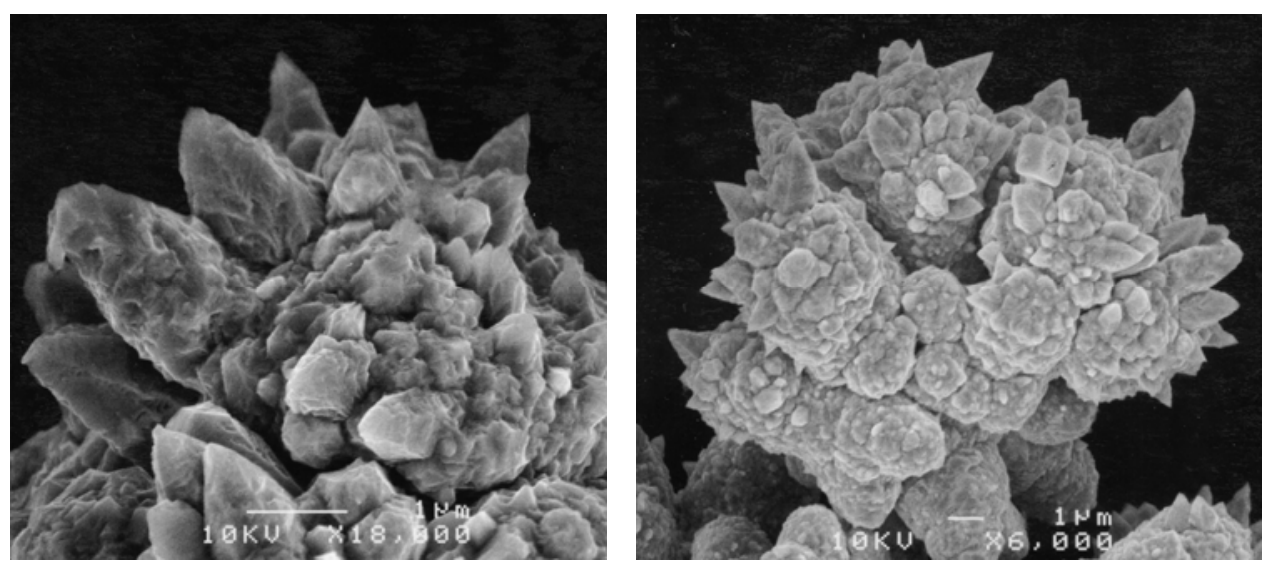

Figure 11. SEM micrographs of $\mathrm{Cu}$ powders produced from an alkaline $\mathrm{CuSO}_{4}$ solution containing sodium potassium tartrate as a complexing agent of $\mathrm{Cu}(\mathrm{II})$ ions and formaldehyde as a reducing agent

This $\mathrm{Cu}$ powder was produced from an alkaline $\mathrm{CuSO}_{4}$ solution containing sodium potassium tartrate as a complexing agent of $\mathrm{Cu}$ (II) ions. The reduction of $\mathrm{Cu}$ (II) complexed ions with formaldehyde is described with the following simple reaction:

$$
\mathrm{Cu}^{2+}+\mathrm{HCOH}+2 \mathrm{OH}^{-} \rightarrow \mathrm{Cu}+\mathrm{HCOOH}+\mathrm{H}_{2} \mathrm{O}
$$

Electroless deposition of copper accompanies the simultaneous hydrogen evolution as it is presented with the reaction below:

$$
2 \mathrm{HCOH}+2 \mathrm{OH}^{-}+\mathrm{Cu}^{2+} \rightarrow 2 \mathrm{HCOOH}+\mathrm{H}_{2}+\mathrm{Cu}
$$

A combination of the equations [7] and [8] leads to:

$$
2 \mathrm{Cu}^{2+}+3 \mathrm{HCOH}+4 \mathrm{OH}^{-} \rightarrow 2 \mathrm{Cu}+3 \mathrm{HCOOH}+\mathrm{H}_{2} \mathrm{O}+\mathrm{H}_{2}
$$

It is obvious from Figure 11 that $\mathrm{Cu}$ powders are agglomerated. The individual particles are predominantly larger than $1 \mu \mathrm{m}$ and they have a very rough surface morphology. 


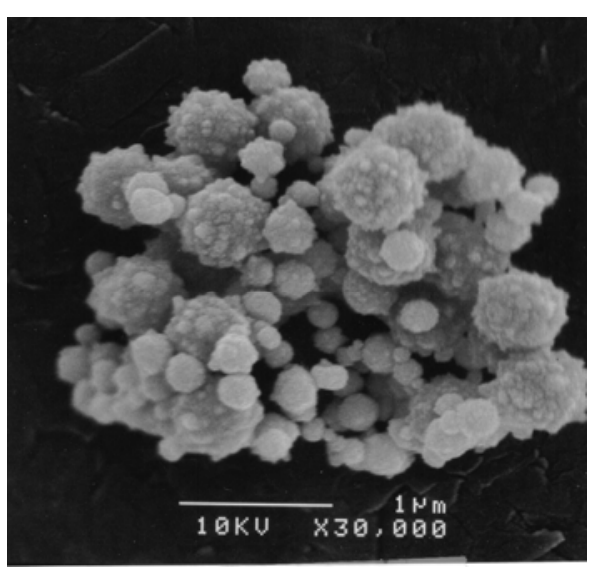

(a)

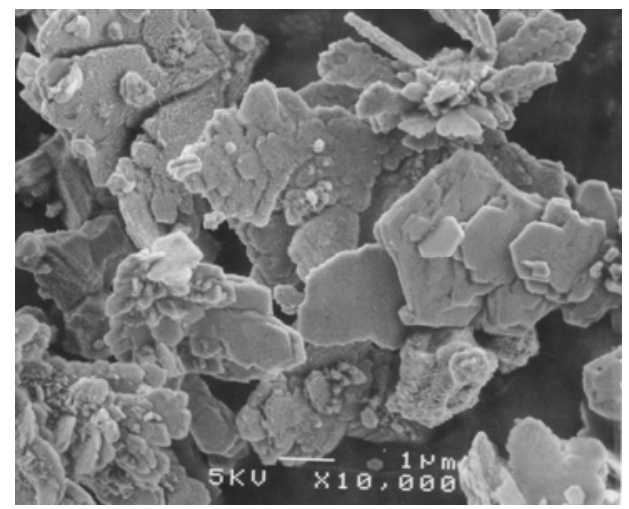

(c)

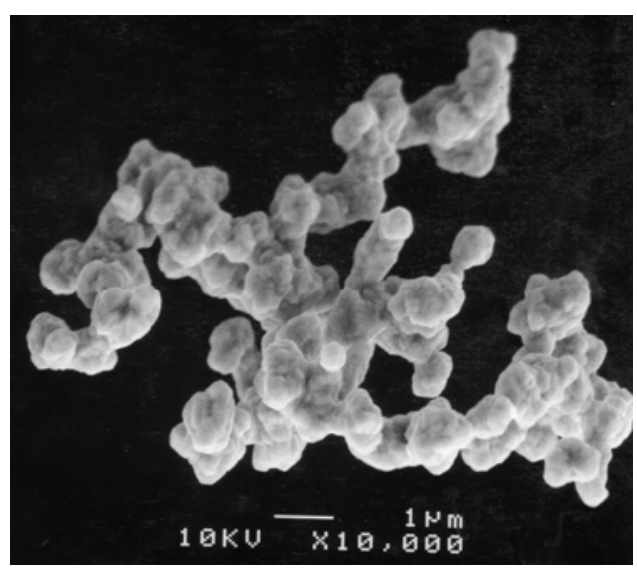

(b)

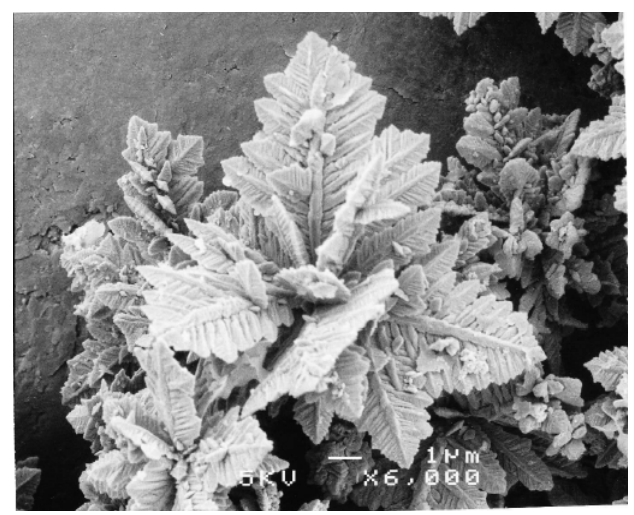

(d)

Figure 12. Powders of (a) nickel, produced by electroless deposition with hydrazine, (b) silver, produced with formaldehyde, (c) cobalt, produced with hypophosphite and (d) cobalt, produced with hydrazine

Similarly, other metallic powders can be produced by the electroless deposition when the bath instability takes place. A few examples such as Ni powder produced with hydrazine, Co powder produced with hydrazine or hypophosphite and Ag powder produced with formaldehyde are presented in Figure 12. Hypophosphite, hydrazine and formaldehyde were used as reducing agents of the respective ions.

Based on the results presented in Figure 12a, the produced nickel particles are agglomerated globules with a rough surface morphology. The size of these particles, according to the SEM image is estimated to be between 100 and $300 \mathrm{~nm}$. Silver powders obtained from an alkaline solution containing $\left[\mathrm{Ag}\left(\mathrm{NH}_{3}\right)_{2}\right]^{+}$and formaldehyde as a reducing agent, based on the SEM image (Figure 12b) represent agglomerates composed of globular silver particles with the size less than $1 \mu \mathrm{m}$. The shapes of Co particles produced by the reduction with hypophosphite (Figure 12c) and hydrazine (Figure 12d) are quite different. While the Co powders deposited via the reaction with hydrazine represent the 3D dendrite, particles produced with hypophosphite are platelets. In both cases the size of the majority of particles is estimated at more than $1 \mu \mathrm{m}$. The difference in shape of Co particles can be attributed to their various chemical compositions. It is 
known that a reduction of $\mathrm{Co}(\mathrm{II})$ ions with hypophosphite leads to the incorporation of phosphorous and formation of amorphous deposits [16], while the reduction with hydrazine produces pure Co (22).

The results presented in Figures 11 and 12 show that the shape, size and morphology of the particles are significantly influenced by the reducing agent and as well as by the nature of the metal deposited.

\section{Deposition of Metallic Powders with Ascorbic Acid as a Reducing Agent}

Many metallic powders can successfully be deposited from aqueous solutions using the reducing agents such as formaldehyde, hypophosphite, borohydride, dimethylamine borane (DMAB) or similar. In the recent few decades significant attention was paid in search for other reducing agents which are more environmentally friendly. In this respect, ascorbic acid as a potential reducing agent of various metallic ions (e.g. silver, gold and copper) is particularly important [12]. In the present work, $\mathrm{Ag}, \mathrm{Cu}$ and $\mathrm{Au}$ powders were produced by electroless deposition from alkaline or acidic solutions using ascorbic acid as the reducing agent.

Particles of silver, produced from a solution of $\mathrm{AgNO}_{3}$ in water (a) and from an alkaline $\left[\mathrm{Ag}\left(\mathrm{NH}_{3}\right)_{2}\right]^{+}$solution (b) with ascorbic acid as the reducing agent are shown by the SEM micrographs in Figure 13. As these images show, there is a significant difference in shapes of silver particles produced in acidic or alkaline solutions using the same reducing agent. In both, acidic (Figure 13a) or alkaline (Figure 13b) solutions the agglomerated powders were obtained. In the acidic solutions platelets or geometric crystals of individual particles of silver, with majority being $1 \mu \mathrm{m}$ in size, or more were found. On the other hand, in the alkaline solutions spherical-like particles with a rough surface morphology were obtained. The size of these spherical particles is less than $1 \mu \mathrm{m}$, with majority being in the range 300 to $500 \mathrm{~nm}$. The difference in shape of produced powders can be attributed to various reaction mechanisms in alkaline and acidic conditions.

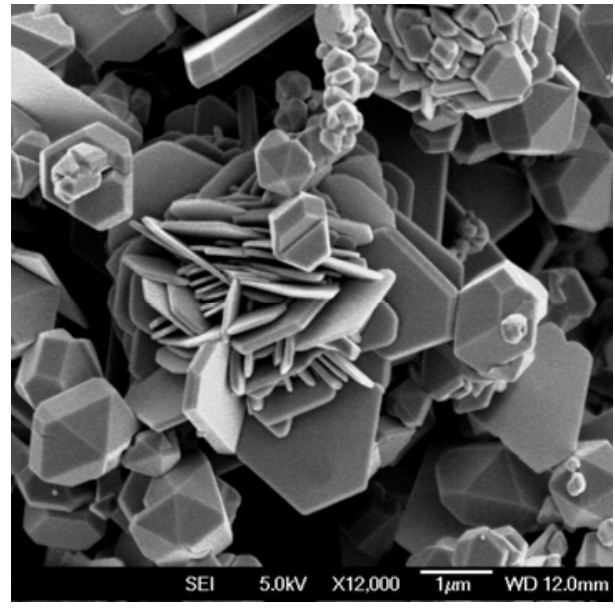

(a)

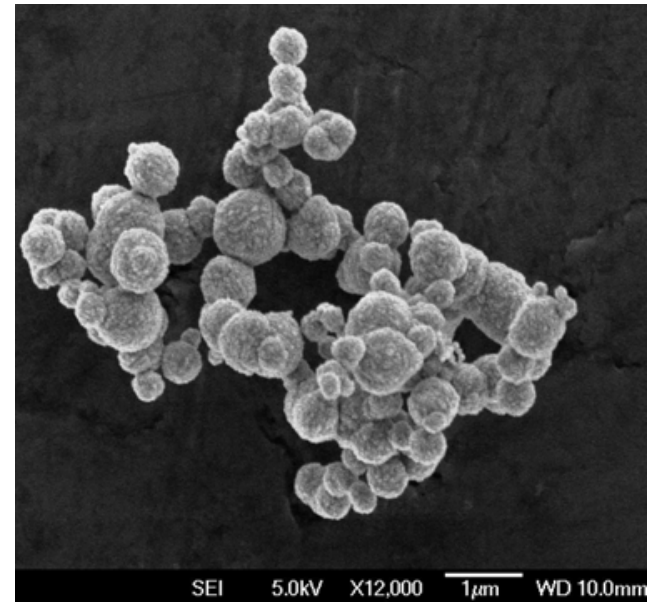

(b)

Figure 13. Particles of silver, produced from (a) solution of $\mathrm{AgNO}_{3}$ in water (a) and from (b) an alkaline $\left[\mathrm{Ag}\left(\mathrm{NH}_{3}\right)_{2}\right]^{+}$solution with ascorbic acid as a reducing agent 
SEM micrographs of $\mathrm{Cu}$ and $\mathrm{Au}$ powders produced from alkaline $\mathrm{CuSO}_{4}$ or acidic $\mathrm{AuCl}_{3}$ solutions, using the ascorbic acid as the reducing agent are presented in Figure 14. As shown in Figure 14a, copper represents agglomerated geometric crystals with a wide range of size between $500 \mathrm{~nm}$ to more than 2-3 $\mu \mathrm{m}$. Gold powder produced with ascorbic acid (Figure 14b) represents agglomerate composed of 3D dendrites, smaller than $500 \mathrm{~nm}$. This result is in a way different from the results published before [23], where the gold particles were found to be star-like. The differences in shape of gold particles are attributed to various conditions including different solutions used in experiments. The palladium powder presented in Figure 14c consists of agglomerates of $\mathrm{Pd}$ particles. It seems that the individual $\mathrm{Pd}$ particles are spheres with a rough surface morphology. The size of the individual particles is estimated at about 300 to $600 \mathrm{~nm}$. This result is different than previously reported images of Pd particles [24] obtained with a reduction of $\mathrm{Pd}(\mathrm{II})$ ions with hypophosphite. While the previous report [24] shows smooth spherical Pd particles, in the present work rough spherical surfaces were obtained. The differences are attributable to various reducing agents used for the deposition of Pd.

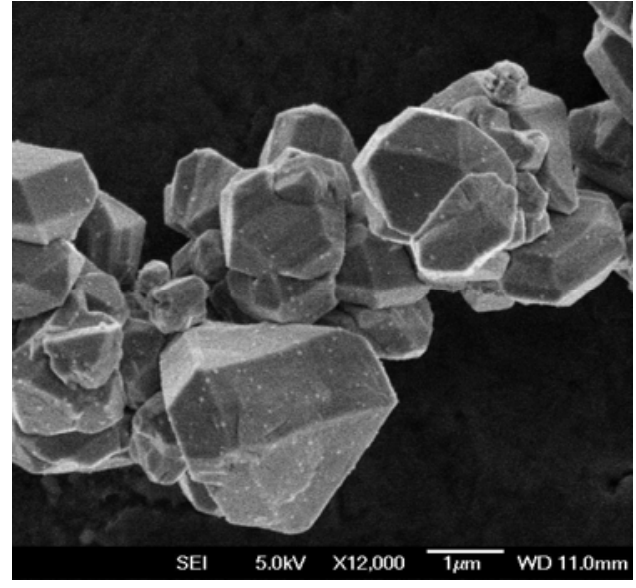

(a)

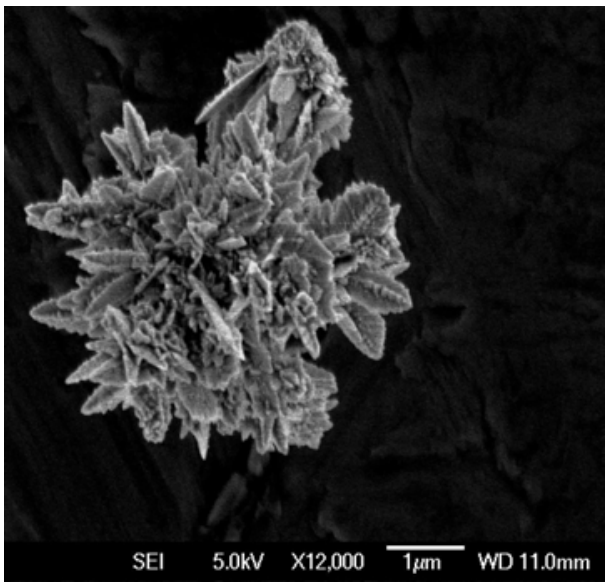

(b)

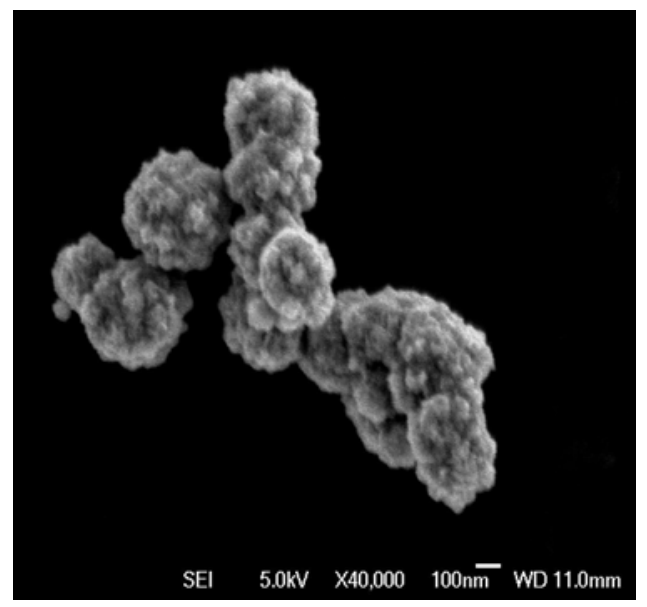

(c)

Figure 14. SEM micrographs of (a) $\mathrm{Cu}$, (b) $\mathrm{Au}$ and (c) $\mathrm{Pd}$ powders produced from $\left[\mathrm{Cu}(\mathrm{NH} 3)_{4}\right]^{2+}, \mathrm{AuCl}_{3}$ and $\left[\mathrm{Pd}\left(\mathrm{NH}_{3}\right)_{2}\right]^{2+}$ solutions respectively, using the ascorbic acid as a reducing agent 
Importantly, the morphologies of powders illustrated in this paper are quite different and depend on the nature of the reducing agent used in the experiments. This can clearly be seen with a comparison of the SEM results presented in Figures 11-14.

An increased concentration of the reducing agent and an elevated temperature significantly contribute to the hydrolysis of the metal ions causing in this way formation of hydroxyl complexes, hydroxides and even oxides. From a homogenous liquid solution the electroless deposition of a metal $\mathrm{M}$, using a reducing agent $\mathrm{R}^{\mathrm{n}-}$ is described with the following reaction:

$$
\mathrm{M}^{\mathrm{z}+}+\mathrm{R}^{\mathrm{n}-} \rightarrow \mathrm{M}+\mathrm{R}^{\mathrm{z}-\mathrm{n}}
$$

In the electroless deposition, the hydrolysis phenomena, as has already been published before $(12,13,16)$, plays a very significant role in the reduction of metallic ions from aqueous solutions. Due to hydrolysis of a metallic ion, the following reaction may occur:

$$
\mathrm{M}^{\mathrm{z+}}+\mathrm{xOH}^{-} \rightarrow \mathrm{M}(\mathrm{OH})_{\mathrm{x}}^{(\mathrm{z}-\mathrm{x})+}
$$

The hydrolyzed metallic species $\left(\mathrm{M}(\mathrm{OH})_{\mathrm{x}}^{(\mathrm{z}-\mathrm{x})+}\right)$ are further reduced in the presence of an appropriate reducing agent $\left(\mathrm{R}^{\mathrm{n}-}\right)$ to metal according to the reaction:

$$
\mathrm{M}(\mathrm{OH})_{\mathrm{x}}^{(\mathrm{z}-\mathrm{x})+}+\mathrm{R}^{\mathrm{n}-} \rightarrow \mathrm{M}+\mathrm{R}(\mathrm{OH})_{\mathrm{x}}^{(\mathrm{z}-\mathrm{x}-\mathrm{n})+}
$$

These hydroxides and/or oxides, formed into the bulk solution due to hydrolysis, serve as sites which are further reduced to the metallic state with an appropriate reducing agent. Since the various sizes of particles can be produced, it is obvious the further growth of the metallic powder is autocatalytic.

To prove the concept that the formation of hydroxides or oxides in the bulk solution leads to their further reduction to the metallic state, several experiments were performed in the following way. Oxide powders, i.e. $\mathrm{Ag}_{2} \mathrm{O}, \mathrm{Cu}_{2} \mathrm{O}$ and $\mathrm{CuO}$ were used as starting materials. Slurries of the mentioned oxides were simply prepared by a dispersion of solid powders in distilled water. The dispersions were vigorously stirred with a magnetic stirrer and an adequate amount of ascorbic acid, used as the reducing agent was added. The mixing was continued until metallic powders (e.g. $\mathrm{Ag}$ and $\mathrm{Cu}$ ) were obtained for approximately 30 minutes, which was visually observed. 


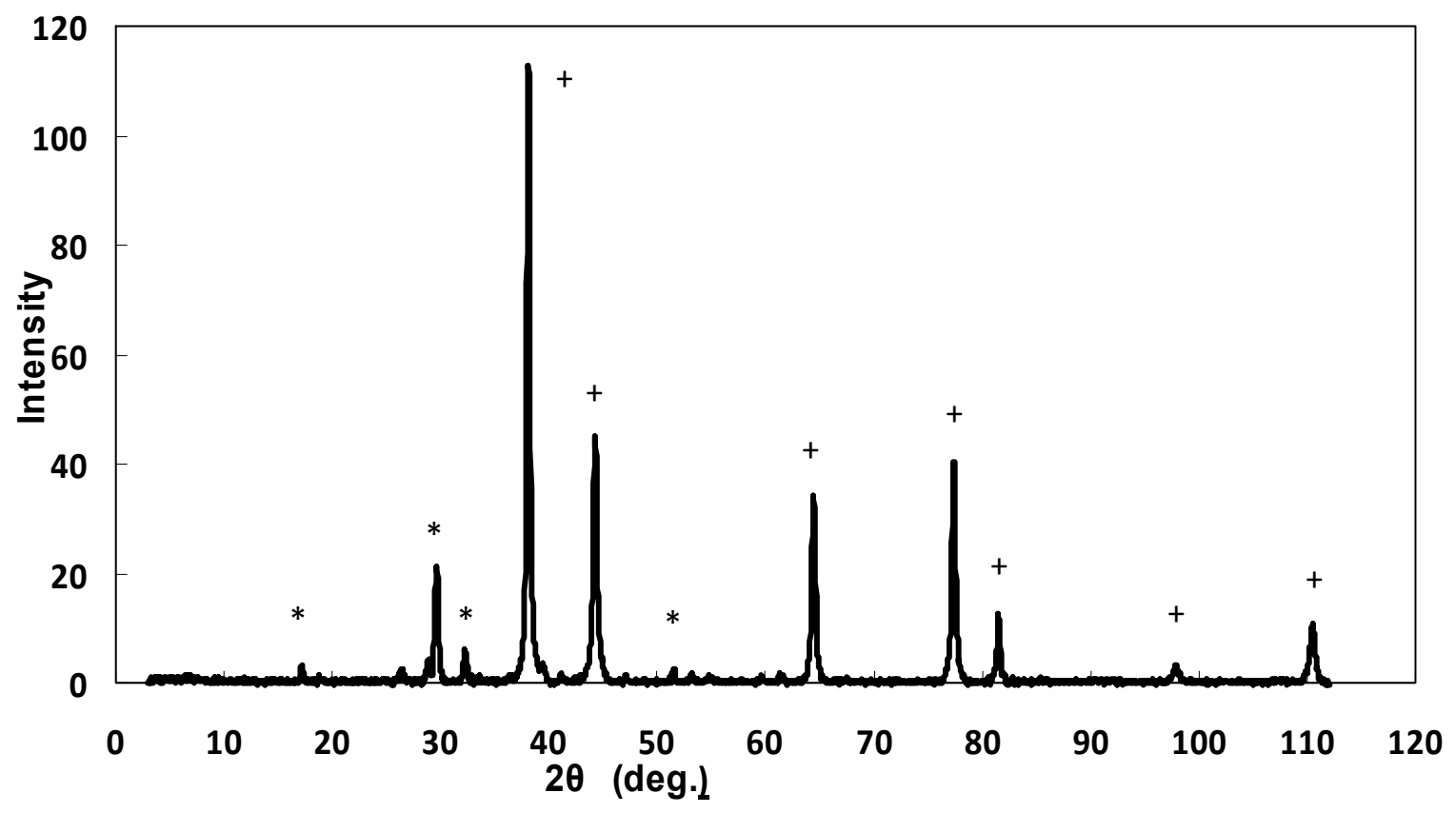

(a)

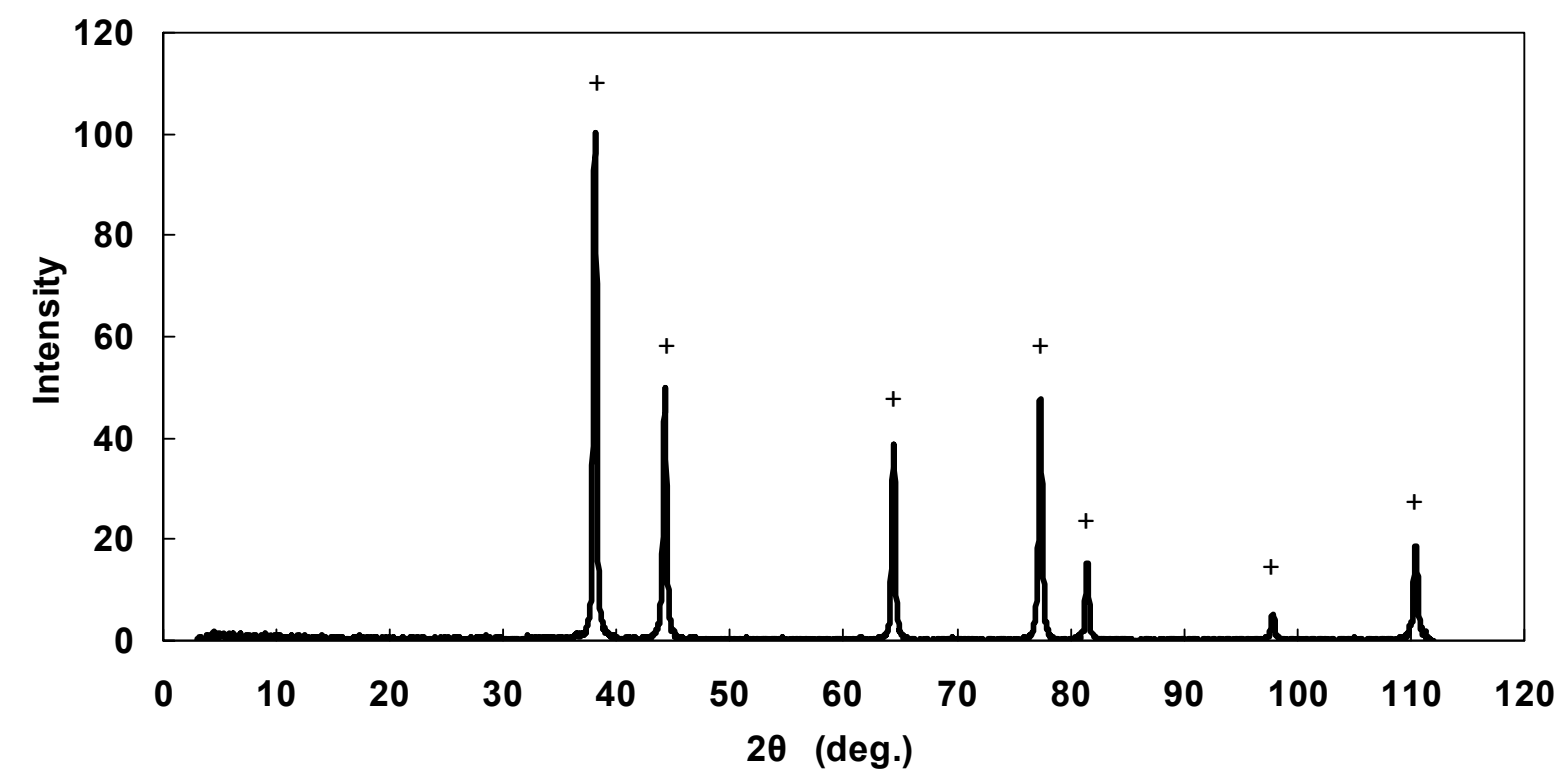

Figure 15. XRD patterns of (a) coarse and (b) fine silver powders produced from a suspension of $\mathrm{Ag}_{2} \mathrm{O}$ and ascorbic acid as a reducing agent $\left(+-\mathrm{Ag}\right.$, * - $\mathrm{Ag}_{2} \mathrm{C}_{2} \mathrm{O}_{4}$ )

XRD patterns of silver powders produced from the slurry of $\mathrm{Ag}_{2} \mathrm{O}$ in water and using the ascorbic acid as a reducing agent are presented in Figure 15 (a) and (b). Both 
patterns (a) and (b) in Figure 15 clearly show $\mathrm{Ag}$ peaks, suggesting that $\mathrm{Ag}_{2} \mathrm{O}$ is reduced to elemental silver. The reduction of $\mathrm{Ag}_{2} \mathrm{O}$ to the elemental silver using the ascorbic acid can be presented as:

$$
\begin{aligned}
& \mathrm{Ag}_{2} \mathrm{O}+\mathrm{H}_{2} \mathrm{O} \rightarrow 2 \mathrm{Ag}^{+}+2 \mathrm{OH}^{-} \\
& \mathrm{Ag}^{+}+\mathrm{OH}^{-} \rightarrow \mathrm{AgOH} \\
& 2 \mathrm{AgOH}+\mathrm{C}_{6} \mathrm{H}_{8} \mathrm{O}_{6} \rightarrow 2 \mathrm{Ag}+\mathrm{C}_{6} \mathrm{H}_{6} \mathrm{O}_{6}+2 \mathrm{H}_{2} \mathrm{O}
\end{aligned}
$$

However, while the pattern (b) shows Ag peaks only, in the pattern (a) (Figure 15), peaks related to silver oxalate $\left(\mathrm{Ag}_{2} \mathrm{C}_{2} \mathrm{O}_{4}\right)$ and silver (II) oxide were identified. This result can be explained as follows.

Ascorbic acid, $\mathrm{C}_{6} \mathrm{H}_{8} \mathrm{O}_{6}$, can be oxidized into the dehydroascorbic acid $\mathrm{C}_{6} \mathrm{H}_{6} \mathrm{O}_{6}$, as presented with the following reaction (25-27):

$$
\mathrm{C}_{6} \mathrm{H}_{8} \mathrm{O}_{6} \rightarrow \mathrm{C}_{6} \mathrm{H}_{6} \mathrm{O}_{6}+2 \mathrm{H}^{+}+2 \mathrm{e}^{-}
$$

The reduction of metallic ions with ascorbic acid should very carefully be carried out, since its consumption in side reactions is also possible. For example, in the oxidation reaction with the dissolved oxygen, which maybe present in the working solution, ascorbic acid is converted into dehydroascorbic acid (28):

$$
\mathrm{C}_{6} \mathrm{H}_{8} \mathrm{O}_{6}+\mathrm{O}_{2} \rightarrow \mathrm{C}_{6} \mathrm{H}_{6} \mathrm{O}_{6}+\mathrm{H}_{2} \mathrm{O}_{2}
$$

In addition, $\mathrm{H}_{2} \mathrm{O}_{2}$ formed during the oxidation, as presented by the reaction [17] reacts with ascorbic acid forming, again, dehydroascorbic acid (25):

$$
\mathrm{C}_{6} \mathrm{H}_{8} \mathrm{O}_{6}+\mathrm{H}_{2} \mathrm{O}_{2} \rightarrow \mathrm{C}_{6} \mathrm{H}_{6} \mathrm{O}_{6}+\mathrm{H}_{2} \mathrm{O}
$$

In this way a significant amount of the ascorbic acid may be consumed during the electroless deposition on side reactions. Furthermore, the complications may arise due to a rapid hydrolysis of dehydroascorbic acid. In fact, it is well established that the hydrolysis of dehydroascorbic acid leads to a formation of the oxalic acid $\left(\mathrm{H}_{2} \mathrm{C}_{2} \mathrm{O}_{4}\right)$ and threonic $\left(\mathrm{C}_{4} \mathrm{H}_{8} \mathrm{O}_{5}\right)$ acids $(25,29)$ as shown with the following reaction:

$$
\mathrm{C}_{6} \mathrm{H}_{6} \mathrm{O}_{6}+3 \mathrm{H}_{2} \mathrm{O} \rightarrow \mathrm{C}_{2} \mathrm{H}_{2} \mathrm{O}_{4}+\mathrm{C}_{4} \mathrm{H}_{8} \mathrm{O}_{5}+\mathrm{H}_{2}
$$

The presence of oxalic acid can lead to the precipitation of silver oxalate according to the reaction:

$$
2 \mathrm{Ag}^{+}+\mathrm{C}_{2} \mathrm{O}_{4}^{2-} \rightarrow \mathrm{Ag}_{2} \mathrm{C}_{2} \mathrm{O}_{4} \downarrow
$$

Silver oxalate is a white precipitate (30) and as such is identified in the pattern (a), Figure 15. Traces of $\mathrm{AgO}$ (Figure 15a) can be attributed to the oxidation $\mathrm{Ag}_{2} \mathrm{O}$. As shown above with the reaction [17] in a side reaction $\mathrm{H}_{2} \mathrm{O}_{2}$, can be formed. The oxidation of $\mathrm{Ag}(\mathrm{I})$ to $\mathrm{Ag}(\mathrm{II})$ with hydrogen peroxide is described in the literature (30). Consequently, the formation of $\mathrm{AgO}$, which is identified in the XRD pattern of the final product (Figure $15(\mathrm{~b}))$, is described as:

$$
\mathrm{Ag}_{2} \mathrm{O}+\mathrm{H}_{2} \mathrm{O}_{2} \rightarrow 2 \mathrm{AgO}+\mathrm{H}_{2} \mathrm{O}
$$


The observations in the present work strongly confirm that the concentration of the ascorbic acid, if used as a reducing agent in the electroless deposition of silver, should very carefully be controlled. It seems that due to consumption of the ascorbic acid on the side reactions, the amount used in the electroless deposition of the corresponding metallic powder should be larger than that required by the stoichiometry.

XRD patterns of the powders produced by the reduction of the aqueous slurries of $\mathrm{Cu}_{2} \mathrm{O}$ and $\mathrm{CuO}$ with the ascorbic acid are presented in Figure 16. It is very clear from the patterns in Figure 16 that only $\mathrm{Cu}$ peaks were identified. No other impurities were found.

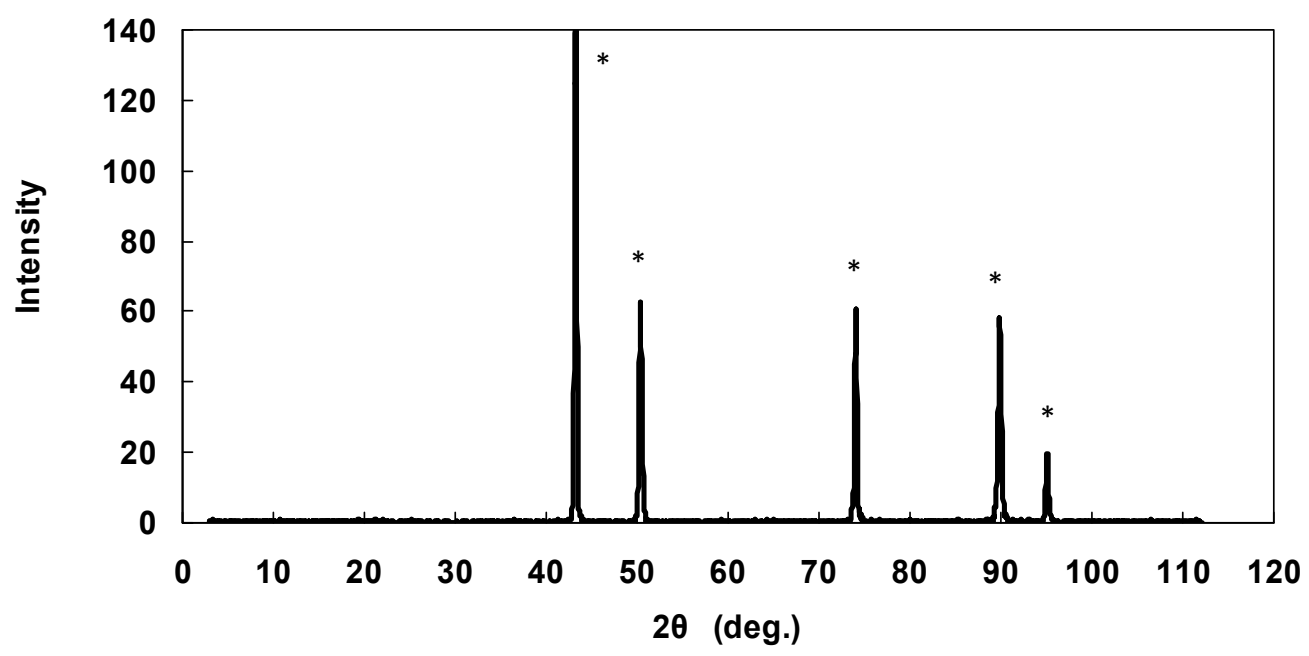

(a)

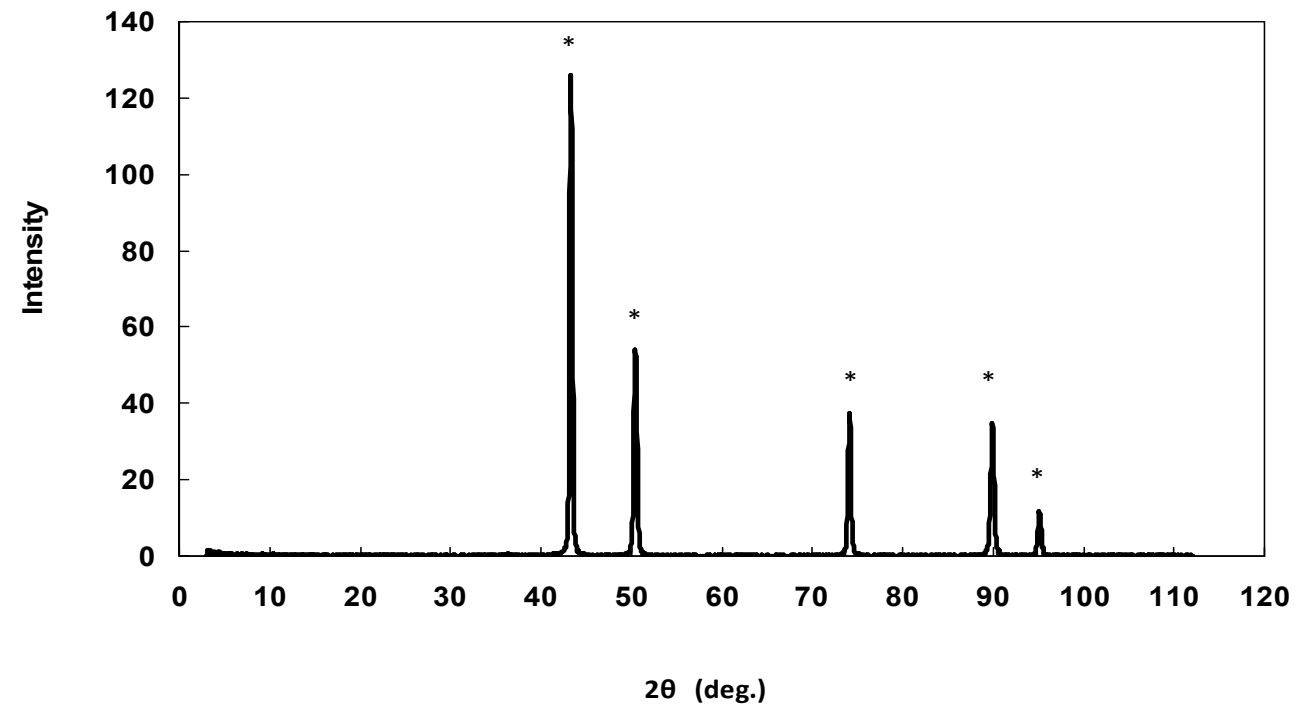

(b)

Figure 16. XRD patterns of copper powders produced from suspensions of (a) $\mathrm{Cu}_{2} \mathrm{O}$ or (b) $\mathrm{CuO}$ and ascorbic acid as a reducing agent $(*-\mathrm{Cu})$ 
The reduction of $\mathrm{Cu}_{2} \mathrm{O}$ or $\mathrm{CuO}$ to the metallic state is explained with the following reactions:

$$
\begin{aligned}
& \mathrm{Cu}_{2} \mathrm{O}+\mathrm{H}_{2} \mathrm{O} \rightarrow 2 \mathrm{Cu}^{+}+2 \mathrm{OH}^{-} \\
& \mathrm{Cu}^{+}+\mathrm{OH}^{-} \rightarrow 2 \mathrm{CuOH} \\
& 2 \mathrm{CuOH}+\mathrm{C}_{6} \mathrm{H}_{8} \mathrm{O}_{6} \rightarrow 2 \mathrm{Cu}+\mathrm{C}_{6} \mathrm{H}_{6} \mathrm{O}_{6}+2 \mathrm{H}_{2} \mathrm{O} \\
& \mathrm{CuO}+\mathrm{H}_{2} \mathrm{O} \rightarrow \mathrm{Cu}^{2+}+2 \mathrm{OH}^{-} \\
& \mathrm{Cu}^{2+}+2 \mathrm{OH}^{-} \rightarrow \mathrm{Cu}(\mathrm{OH})_{2} \\
& \mathrm{Cu}(\mathrm{OH})_{2}+\mathrm{C}_{6} \mathrm{H}_{8} \mathrm{O}_{6} \rightarrow \mathrm{Cu}+\mathrm{C}_{6} \mathrm{H}_{6} \mathrm{O}_{6}+2 \mathrm{H}_{2} \mathrm{O}
\end{aligned}
$$

a) $\mathrm{Cu}$ from $\mathrm{Cu}_{2} \mathrm{O}$

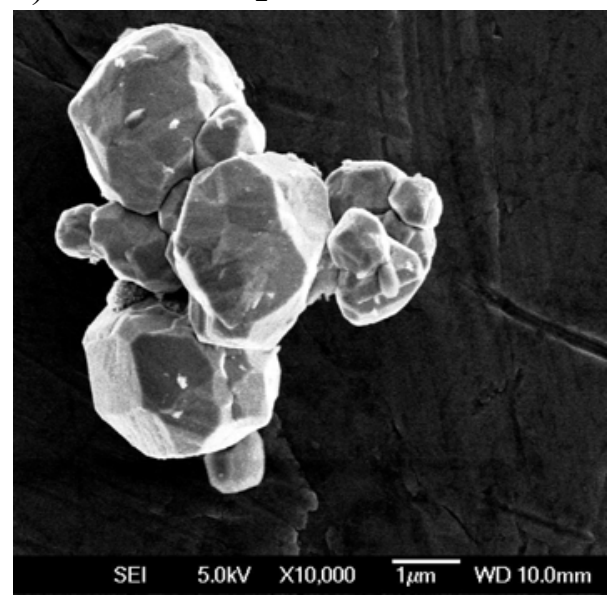

c) $\mathrm{Ag}$

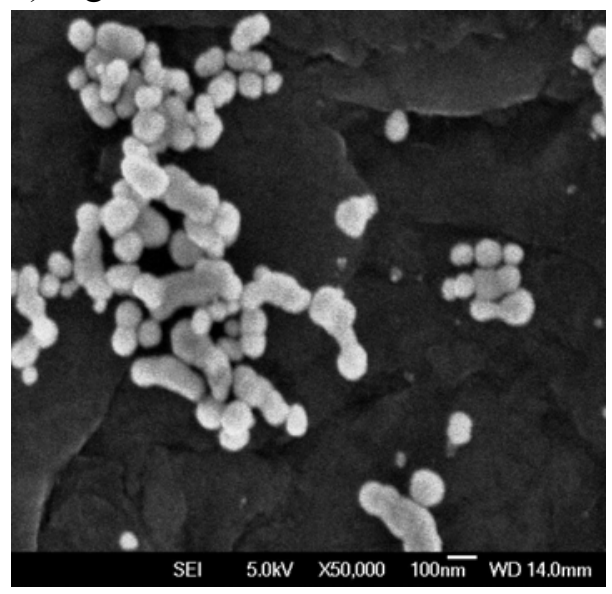

b) $\mathrm{Cu}$ from $\mathrm{CuO}$

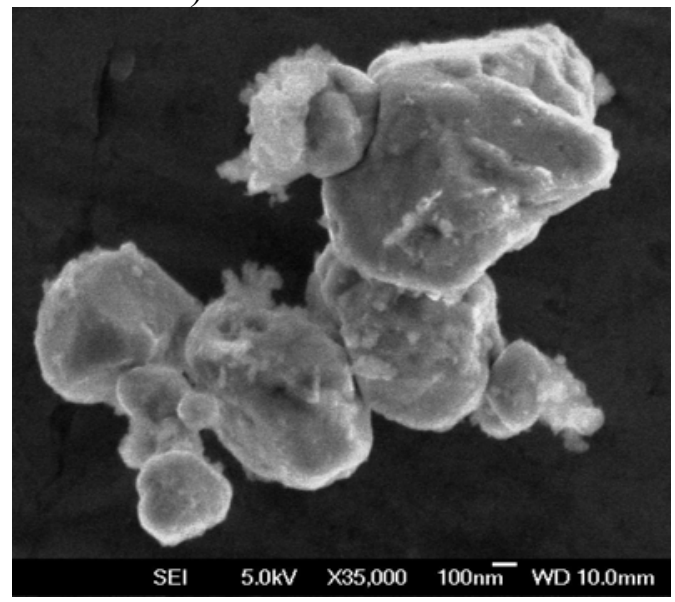

d) $\mathrm{Ag}$

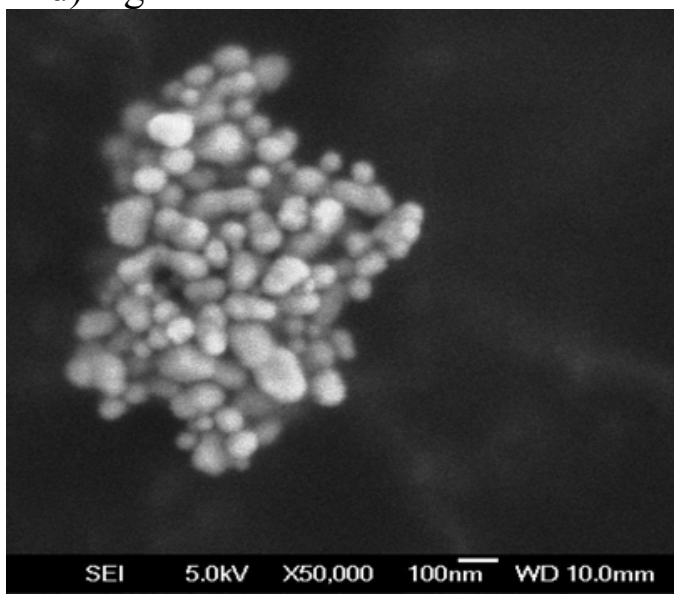

Figure 17. Copper and silver powders produced by the reduction of $\mathrm{Cu}_{2} \mathrm{O}(\mathrm{a}), \mathrm{CuO}(\mathrm{b})$ and $\mathrm{Ag}_{2} \mathrm{O}$ (c and d) with ascorbic acid 
The SEM images of silver and copper powders produced by the reduction of the respective oxides with ascorbic acid are presented in Figure 17. In both cases, i.e., when the starting material was $\mathrm{Cu}_{2} \mathrm{O}$ or $\mathrm{CuO}$, similar shapes of $\mathrm{Cu}$ particles were obtained. The results presented in Figures 17a and 17b show that the $\mathrm{Cu}$ particles obtained via reduction of $\mathrm{Cu}_{2} \mathrm{O}$ or $\mathrm{CuO}$ with ascorbic acid are geometric crystals with sizes from 500 $\mathrm{nm}$ to about $2 \mu \mathrm{m}$. Silver powder (Figures $17 \mathrm{c}$ and $17 \mathrm{~d}$ ), produced via reduction of $\mathrm{Ag}_{2} \mathrm{O}$ with ascorbic acid as a reducing agent represents agglomerates of nanoparticles. The individual size of these nanoparticles is about $100 \mathrm{~nm}$ or less.

\section{Conclusions}

Electrodeposition of copper and silver powders under the potentiostatic conditions is seen at overpotentials higher and/or those belonging to the plateau of the limiting diffusion current. In the case of copper, formation of powders is accompanied with the simultaneous hydrogen evolution. The amount of hydrogen evolved significantly influences the surface morphology of copper powders. While at lower overpotentials very branched dendrites were obtained, at higher overpotentials, where the vigorous hydrogen evolution takes place, honeycomb-like powdered deposits were produced. The smaller size of the individual copper grains at higher overpotentials is attributable to an increased rate of nucleation. The simultaneous hydrogen evolution was not observed during the electrodeposition of silver powders. Formation of silver powders by electrodeposition is characterized by the comparison of the exchange $\left(\mathrm{i}_{\mathrm{o}}\right)$ and limiting $\left(\mathrm{i}_{\mathrm{L}}\right)$ current densities. Instantaneous growth of dendrites starts at relatively low overpotential because of the large exchange current density in silver nitrate solution, which is significantly higher than in the case of silver ammonium solution. The surface morphology of silver powders is dependent on the kind of anion used.

Using the electroless deposition, metallic powders can be obtained via a few different approaches. Galvanic deposition of metallic powders is achieved as a consequence of the porosity of more positive metal or a simultaneous hydrogen evolution reaction. From homogenous solutions, many metallic powders can be produced when the instability of the solution takes place. This is seen when the concentration of the reducing agent is too high or at elevated temperatures. Formation of metallic powders (e.g. $\mathrm{Ni}, \mathrm{Co}, \mathrm{Ag}$ and $\mathrm{Pd}$ ) using an appropriate reducing agent from homogenous aqueous solutions was demonstrated in the present work. The observations suggest that the hydrolysis of metallic ions is crucial in the deposition of metallic powders via electroless deposition from homogenous aqueous solutions. It was shown that if starting sources of metallic ions are oxides (e.g. $\mathrm{Ag}_{2} \mathrm{O}, \mathrm{CuO}$ and $\mathrm{Cu}_{2} \mathrm{O}$ ), using an appropriate reducing agent (ascorbic acid in the present work), metallic powders ( $\mathrm{Ag}$ or $\mathrm{Cu}$ ) can successfully be produced.

It seems that in both electrodeposition and electroless deposition, depending on the metal being deposited, the simultaneous hydrogen evolution reaction or hydrodynamic conditions significantly influence the formation of powders. We believe that future studies in this area would lead to the more sophisticated findings of the reaction mechanisms for the powders described in the present work. 


\section{Acknowledgments}

The electrodeposition part of this work was supported by the Ministry of Science and Technological Development of the Republic of Serbia (No. 172046). For the experimental help in electroless deposition, Djokić is thankful to Dr. H. Wan from the University of Alberta.

\section{References}

1. R.M. German, Powder Metallurgy Science ( $2^{\text {nd }}$ edition), Metal Powder Industries Federation, Princeton, New Jersey, 1994.

2. A. Calusaru, Electrodeposition of Metal Powders, Materials Science Monographs, Vol. 3, Elsevier, New York, 1979.

3. N. Ibl, The Formation of Powdered Metal Deposits, in "Advances in Electrochemistry and Electrochemical Engineering" Vol. 2, pp 50-142, P. Delahay and C. W. Tobias (editors), Interscience, New York, 1962.

4. A.R. Despić, K.I. Popov, „Transport Controlled Deposition and Dissolution of Metals", in Modern Aspects of Electrochemistry, Vol. 7., B.E. Conway and J.O'M. Bockris, Eds., Plenum Press, New York, pp. 199-313, 1972.

5. K.I. Popov, M.G. Pavlović, M.D. Maksimović, J. Appl. Electrochem. 12, 525 (1982).

6. K.I. Popov, N.V. Krstajić, M.I. Čekerevac, „The Mechanism of Formation of Coarse and Disperse Electrodeposits“, in Modern Aspects of Electrochemistry, R.E. White, B.E. Conway and J.O’M. Bockris, Eds., Plenum Press, New York, pp. 261-311, 1996.

7. K.I. Popov, S.S. Djokić, B.N. Grgur, Fundamental Aspects of Electrometallurgy, Kluwer Academic/Plenum Publishers, New York, 2002.

8. N.D. Nikolić, K.I. Popov, Lj.J. Pavlović, M.G. Pavlović, J. Electroanal. Chem. 588, 88 (2006).

9. N.D. Nikolić, K.I. Popov, Lj.J. Pavlović, M.G. Pavlović, Sensors, 7, 1 (2007).

10. N.D. Nikolić, Lj.J. Pavlović, M.G. Pavlović, K.I. Popov, Powder Technology 185, 195 (2008).

11. M.G. Pavlović, K.I. Popov, Metal Powder Production by Electrolysis, Electrochemistry Encyclopedia, http://electrochem.cwru.edu/ed/encycl/art-p04metalpowder.htm, (December, 2005).

12. S. S. Djokić, Electroless Deposition of Metals and Alloys, in Modern Aspects of Electrochemistry, Number 35, Edited by B. E. Conway and R.E. White, p.51, Kluwer Academic/Plenum Publishers, 2002.

13. S. S. Djokić and P.L. Cavallotti, Electroless Deposition: Theory and Applications, in Modern Aspects of Electrochemistry, 48, Edited by S. S. Djokić, p.250, Springer, 2010.

14. S. S. Djokić, J. Electrochem Soc., 143, 1300 (1996).

15 S. Djokić and N. Djokić, in Abstract 2764, 214th Meeting of the Electrochemical Society, Honolulu, Hawaii, October 12-17, 2008.

16. O. Mallory and J.B. Hajdu, Electroless Plating: Fundamentals and Applications, AESFS, Orlando, FL, 1990.

17. N.D. Nikolić, Lj.J. Pavlović, M.G. Pavlović, K.I. Popov, Electrochim. Acta 52, 8096 (2007).

18. K.I. Popov, M. Vojnović, G. Rikovski, Hemijska Industrija 8, 1392 (1968)(in Serbian). 
19. S. Trasatti, J. Electroanal. Chem. 39, 163 (1972).

20. P.B. Price, D.A. Vermilyea, J. Chem. Phys. 28, 720 (1958).

21. K.I. Popov, N.V. Krstajić, S.R. Popov, Surf. Technol. 22, 245 (1984).

22. S. S. Djokić, J. Electrochem Soc. ,144, 2385 (1997)

23. S.S. Djokić , in "Fundamental Aspects of Electrochemical Deposition and Dissolution", Proc. Vol. 99-33, pp.381 - 396, The Electrochem Society, Inc., Pennington, N.J., 2000.

24. S.S. Djokić, Plat. and Surface Finish., 86 (6), 104 (1999).

25. R. R. Grinstead, J. Am. Chem. Soc., 83, 3464 (1960).

26. D. E. Hughes, Anal. Chem., 57, 555 (1985).

27. D. E. Hughes and S. Van Densen, Analyst, 114, 169 (1989).

28. M. Liao and P.A. Seib, Food Technology, 41, 104 (1987).

29. R. R. Rucker and G. M. Mayers-Steiberg in Encyclopedia of Human Biology, Vol. 1, Dulbeco Editor, p. 428, The Salk Institute La Jolla, CA and Academic Press Inc., New York (1991).

30. N.R. Thompson in Comprehensive Inorganic Chemistry, Vol. III D, J.C. Bailer, Emeléus, R. Nyholm, and A.F. Trutman-Dickemson, Editors, Pergamon Press, Oxford (1973). 